\title{
The key role of the Northern Mozambique Channel for Indian Ocean tropical tuna fisheries
}

\author{
Chassot Emmanuel 1, 2, ${ }^{*}$, Bodin Nathalie ${ }^{1}$, Sardenne Fany ${ }^{3}$, Obura David ${ }^{4}$
}

${ }^{1}$ Seychelles Fishing Author, POB 449, Victoria, Mahe, Seychelles.

2 Univ Montpellier, MARBEC, CNRS, Ifremer,IRD, Victoria, Seychelles.

${ }^{3}$ Fisheries \& Oceans Canada, Maurice Lamontagne Inst, Mont Joli, PQ, Canada.

${ }^{4}$ CORDIO East Africa, Mombasa, Kenya.

* Corresponding author : Emmanuel Chassot, email address : manu.chassot@gmail.com

\begin{abstract}
:
The Northern Mozambique Channel (NMC) is a tropical area of similar to 1 million $\mathrm{km}(2)$ where pelagic fisheries supply proteins to more than 9 million people living in Comoros, Mayotte, and along the coasts of Mozambique, Tanzania and Madagascar. Although uncertain, statistics suggest that about 20,000 mt of tropical tuna and other pelagic fish are annually caught by artisanal fisheries in the area. The NMC is also a major seasonal fishing ground for high-seas fleets that export an annual average catch of more than 20,000 mt to tuna can and sashimi markets of high-income countries for a value estimated to be more than 100 million USD. The fisheries productivity of the NMC appears to be highly variable in relation to strong annual and seasonal variability in oceanographic conditions. Our review shows that the NMC is a key feeding area for tropical tunas and a major spawning area for skipjack tuna thanks to warm waters and strong mesoscale activity that results in the enrichment of surface waters and efficient energy transfers enabled by short food chains. Projections of climate models under future warming scenarios predict some strong changes in the oceanographic conditions of the NMC which has already experienced substantial warming over the last decades. Changes in the pelagic ecosystem of the NMC could have dramatic consequences on the coastal populations that are expected to increase towards 100 million people by 2100. Improving monitoring systems and collecting information on the socio-economics of coastal fisheries is crucial to assess the dependence of NMC populations on tuna resources and empower the countries to more involvement in the management of tuna stocks.
\end{abstract}

Keywords : Bigeye, Fisheries management, Mozambique Channel, Skipjack, Yellowfin 
34 Acknowledgements We are grateful to all the people involved in the collection and management of

35 the data used in the present study, in particular the staff of the IOTC Secretariat for their dedication

36 to their work. Special thanks to Fabio Fiorellato, James Geehan, Lucia Pierre, and Dan Fu. Catch

37 and effort data were extracted from the global tuna fisheries database initiated by Alain and Viceca

38 Fonteneau and further developed and consolidated through a collaboration between FAO and IRD.

39 Liam Campling provided information on international tuna prices (FFA Trade Bulletin). We are

40 grateful to the many persons involved in the Tuna Atlas project, in particular Paul Taconet, Julien

41 Barde, Emmanuel Blondel, Aymen Charef and Marc Taconet. The database and services of the Tuna

42 Atlas are currently hosted by the Institute of Information Science and Technologies (CNR-ISTI) and

43 the work received funding from the European Union's Horizon 2020 research and innovation

44 programme under the BlueBRIDGE project (Grant agreement No 675680). The tuna tagging data

45 analysed in this publication were collected by the Regional Tuna Tagging Project of the Indian

46 Ocean (RTTP-IO) funded under the 9th European Development Fund (9.ACP.RSA.005/006) of

47 the European Union. The RTTP-IO was implemented by the Indian Ocean Commission under

48 the technical supervision of the IOTC. We wish to acknowledge the contributions of the project

49 staff and all the technicians, recovery officers and fishers that have been involved in the RTTP-

50 IO. Reproduction and morphometric data were mostly collected through the project EMOTION 
51 founded by the French National Research agency (ANR 11 JSV7 007 01), the EU Data

52 Collection Framework (Reg. 199/2008 and 665/2008), Fundación Centros Tecnológicos,

53 Department of Agriculture, Fisheries and Food of the Basque Government, and the PEVASA

54 fishing company. James Mbugua (CORDIO) provided assistance with NMC boundaries and

55 Umair Shahid useful comments on an earlier version of the manuscript. Many thanks to

56 Pierrick Penven for pointing out very useful references on the oceanographic features of the

57 Northern Mozambique Channel and Simon Hoyle for discussions and advice on statistical

58 models. Laurent Pinault provided information on fisheries agreements. We finally thank the

59 two anonymous reviewers for their constructive comments that helped improve the

60 manuscript. The present study was funded by a WWF grant as part of the Northern

61 Mozambique Channel Initiative. 


\section{Introduction}

63 The Northern Mozambique Channel (NMC) is the part of the Mozambique Channel northwards of

64 the narrowest stretch between Madagascar and Mozambique. The NMC is bounded by northwest

65 Madagascar, northern Mozambique and southern Tanzania, with the Comoros archipelago at its

66 heart. The Aldabra group of islands lies just to the north at about $9^{\circ} \mathrm{S}$. In its wider definition, the

67 northern limit of the NMC is operationally set to include Mafia Island in central Tanzania at about

$687^{\circ} \mathrm{S}$ while its southern limit goes down to $19^{\circ} \mathrm{S}$ (Obura et al. 2015) (Fig. 1). The NMC is described

69 by a high diversity of marine habitats typical of shallow tropical seas, including coral reefs,

70 mangrove forests, seagrass beds, and a dynamic pelagic zone which constitutes a major habitat for

71 tropical tuna (Obura et al. 2015). Historical statistical data on artisanal fishing for subsistence are

72 sparse and uncertain for the countries bordering the NMC but available information suggests that

73 large pelagic species have long been a very small component of traditional fisheries since they were

74 restricted to the nearshore zone (Petit 1923; Fourmanoir 1954). Reviews available for coastal

75 fisheries of the NMC show that they are essentially supported by inshore fisheries (coral reef,

76 mangroves, etc.) as well as shrimp fisheries in the case of Madagascar (van der Elst et al. 2005; De

77 Young 2006). Tuna fisheries statistics for coastal and high seas fishing nations go back to the early

78 1950s with the expansion of the Japanese longline fleet across the Indian Ocean, including the

79 Mozambique Channel (Geehan et al. 2016). In the early 1970s, some exploratory cruises were

80 conducted by Japanese and French vessels along the coasts of Madagascar, Comoros, and

81 Seychelles to assess the potential for development of a commercial tuna fishery in the region

82 (Marcille and Veillon 1973). Following the implementation of the United Nations Convention on

83 the Law of the Sea (UNCLOS) in December 1982 concurrently with the arrival of a major purse

84 seine fleet from the Atlantic Ocean, a major seasonal surface fishery developed in the NMC from

851985 (Stéquert and Marsac 1989). Fishing agreements to access the national waters of the NMC

86 coastal countries by the European Union fishing fleets date back to 1986, 1987, and 1988 for 
87 Madagascar, Mozambique, and Comoros, respectively. Since then, the NMC area has become a

88 major fishing ground for the tropical Indian Ocean tuna purse seine fishing fleets with catches

89 corresponding to more than $30000 \mathrm{mt}$ per year over the last three decades, i.e. about $10 \%$ of their

90 annual production.

92 The management of Indian Ocean tropical tunas is under the jurisdiction of the Indian Ocean Tuna

93 Commission (IOTC) since 1996 (Kambona and Marashi 1996). Its overarching objective is to

94 maintain the stocks of tuna and tuna-like species at levels which allow maximum sustainable yield.

95 The core work of the IOTC Secretariat is to collate and manage multiple fisheries data sets of catch,

96 effort, and size provided by each Commission member to support the assessment of the status of the

9716 species under the IOTC mandate and develop and implement conservation and management

98 measures such as effort or catch limitation to ensure their sustainability. The IOTC is however faced

99 with major issues in both the quantity and the quality of the data provided by the contracting parties

100 and the conservation measures and stock assessments are developed with partial information

101 (Fiorellato et al. 2018; IOTC 2018). The three principal market tunas that represented more than

$10250 \%$ of the catch of all IOTC species over the last decade are skipjack (Katsuwonus pelamis;

103 26\%), yellowfin (Thunnus albacares; 22\%), and bigeye (Thunnus obesus; 7\%) tuna,

104 characterized by small to medium size, rapid growth, early age-at-maturity, and long spawning

105 duration (Juan-Jordá et al. 2013; Murua et al. 2017). These highly migratory species can carry out

106 fast and extensive movements and migrations in search of a large variety of prey to address their

107 high energetic needs and fuel reproduction. Tropical tunas generally occur in mixed schools that can

108 be composed of tens of thousands of fish in the case of fishing sets exceeding $100 \mathrm{t}$ and composed

109 of tuna of average weights 3-5 kg that are generally associated with floating objects (Chassot et al.

110 2015). This schooling behaviour combined with their associative behaviour with floating objects

111 (Fréon and Dagorn 2000; Castro et al. 2002) has a major influence on the spatio-temporal dynamics 
112 of the purse seine fishery (Kaplan et al. 2014; Davies et al. 2014) and might affect their growth,

113 mortality and reproduction, although this needs to be further explored (Marsac et al. 2000; ISSF

114 2014). Schooling behaviour could also play a major role in stabilizing tuna populations (Maury

115 2017).

117 More than 9 million people currently live within the Comoros Archipelago and along the coasts of

118 Mozambique, Tanzania and Madagascar that border the NMC (Obura et al. 2018). This population

119 is expected to increase by close to an order of magnitude towards 100 million people by 2100,

120 which will result in exponential increases in demands and pressures on natural resources (Obura et

121 al. 2018). In parallel, projections of climate models under future warming scenarios suggest the

122 strengthening of the Somali coastal upwelling due to increased ocean-land thermal gradient in

123 conjunction with weakened nutrient mixing at regional scale because of enhanced ocean

124 stratification (Roxy et al. 2016; deCastro et al. 2016). Long-term analysis of oceanographic data

125 already showed that the western Indian Ocean has been warming for more than a century, at a rate

126 faster than any other region of the tropical ocean, which resulted in a major decrease in primary

127 productivity over the last decades due to weakened nutrient mixing and reduction of chlorophyll

128 concentrations over most of the Arabian Sea (Roxy et al. 2014, 2016). Changes in marine

129 ecosystems due to warming could deteriorate the habitat of tuna and modify their distribution and

130 abundance in the Indian Ocean (Dueri et al. 2014).

132 In this context, it is essential to assess the magnitude and economic importance of pelagic resources

133 exploited within the NMC for both the foreign markets of canned and sashimi tuna and the

134 livelihoods of coastal communities that are directly dependent on the region's natural marine and

135 coastal assets. The overarching objective of the present study is to review the available knowledge

136 on tuna biology, ecology and fisheries in the NMC to describe the specific features of this region 
137 and its importance with regards to the whole Indian Ocean and evaluate the importance of tuna

138 resources on the domestic communities.

\section{Materials \& Methods}

141 Public-domain data sets of total annual catch, monthly-spatially aggregated catch, effort, and size 142 collated from the IOTC Secretariat were available from the IOTC website (www.iotc.org) and used 143 to characterize the spatio-temporal patterns of tuna fisheries in the NMC area (Fig. 1). Here, we

144 follow the definitions of fisheries employed by the IOTC and use indifferently coastal and artisanal 145 for any fishing vessel less than $24 \mathrm{~m}$ that operates within its national Exclusive Economic Zone 146 (EEZ). No detailed information is available from the IOTC about the number of artisanal vessels as 147 the IOTC registry of fishing vessels only includes vessels that are larger than $24 \mathrm{~m}$ in length overall 148 and vessels less than $24 \mathrm{~m}$ that operate in waters outside the economic exclusive zone of the flag 149 state and that are authorized to fish for tuna and tuna-like species within the IOTC area of 150 competence. Data reported by the national fisheries of Comoros, Madagascar, Mayotte, 151 Mozambique, and Tanzania are not geo-referenced, with the exception of data from Mozambican 152 sport fisheries in 2016. Annual catch reported to the IOTC by these countries was assumed to 153 originate from their national waters since they essentially have coastal fleets operating within their 154 respective EEZ all year round (Geehan and Fiorellato 2017). The total tuna catch of coastal fisheries 155 within the NMC was computed by assuming that the catch of each country was evenly distributed 156 within their respective EEZ, i.e. the catch was weighted by the proportion of each EEZ within the NMC boundaries (Fig. 1). Mayotte and Comoros are fully included in the NMC and the proportions of EEZ within the NMC area are 20\%, 32\%, and 44\% for Madagascar, Mozambique, and Tanzania, respectively (Table 1). Overall, the national waters of Madagascar represent 33\% of the NMC, 160 followed by Mozambique (24\%) and Comoros (21\%) while Tanzania and Mayotte only represent $16114 \%$ and $8 \%$ of the area, respectively (Table 1). Quantitative information on recreational sport 
162 fisheries is very scarce within the NMC area while these fisheries target oceanic pelagic species

163 such as tunas and billfishes (Pepperell et al. 2017). Also, no information is currently available from

164 non-commercial small-scale fishing that is mainly conducted for subsistence within this region.

166 Data reported by high seas fishing fleets have a spatial resolution of $1^{\circ}$ and $5^{\circ}$ grids for purse

167 seiners and longliners, respectively. Time-area catches were first raised to the total catch to account

168 for some gaps in reporting and then allocated to the NMC proportionally to the area of each grid 169 cell within the NMC area ${ }^{1}$. Uncertainty on catch was estimated through lower and higher bounds 170 where the lower bound excludes all the catch reported within a cell grid that includes a part of area 171 outside the NMC while the higher bound includes it. Official catch statistics available from the 172 IOTC were considered to constitute the best available information for both coastal and high seas 173 fisheries occurring in the NMC. It should be noted, however, that generally these values do not 174 include figures for tuna discarded at sea (Martin et al. 2016). Moreover, under- and misreporting 175 issues have been identified, particularly in artisanal fisheries in which the species composition is not 176 corrected through port sampling despite some systematic bias due to anatomical similarity between 177 juveniles of yellowfin and bigeye tunas (Fiorellato et al. 2018).

179 Time series of economic data for tuna fisheries are scattered, difficult to access, and generally not 180 available across fisheries (Galland et al. 2016). A preliminary estimate of the total annual value of 181 the tuna catch from foreign fleets operating within the NMC was obtained based on the monthly 182 average prices of purse-seine frozen tuna imported in Thailand (http://www.customs.go.th) and 183 longline frozen tuna imported in Japan (L Campling, pers. comm.). This value overestimates the 184 value paid to the fishermen as it includes additional costs of international freight and tax fees (i.e. 185 Cost-Insurance-Freight) as compared to Free On Board prices which were not available for the present study. Also, an increasing, but still minor, part of the purse seine catch is now destined to

81 The processing steps and resulting data set are fully described here: https://doi.org/10.5281/zenodo.1164128. 
187 higher-value tuna products such as loins and steaks with the development of deep-freezing storage

188 onboard several purse seiners in recent years. The part of the catch as well as price information for 189 these products remain confidential for competitive reasons. For these reasons and due to the 190 uncertainties associated with estimates of catch from IOTC spatially-aggregated data, in particular 191 for longline, estimates of catch value should be considered with great caution. They are mainly used 192 here to provide general figures of the importance of the NMC for high seas fisheries.

194 Information on stock delineation, movements, growth, reproduction, and trophic ecology of Indian 195 Ocean tropical tunas was retrieved from the literature, including peer-review articles and reports of 196 IOTC working groups and Scientific Committees. Growth, maturity and natural mortality at age 197 used in stock assessment models for skipjack, bigeye, and yellowfin were available from the IOTC 198 Secretariat (Langley 2015, 2016a, b; Fu and Fiorellato 2017). Movements between large areas are 199 estimated as part of the assessments of the status of yellowfin and bigeye while the current 200 configuration of the skipjack stock assessment model does not include any spatial stratification (Fu 201 and Fiorellato 2017). In addition, the apparent horizontal movements and daily growth rates of the 202 three species tagged within the NMC were analysed from the mark-recapture data set collected 203 throughout the Indian Ocean Tuna Tagging Programme (IOTTP) (Supplementary Online Materials).

\section{Setting the oceanographic scene}

The Mozambique Channel plays a major role in the circulation of the Indian Ocean through the meridional flow of water from the tropical to the sub-tropical regions in the southern Indian Ocean

208 (Ganachaud et al. 2000; Schott et al. 2009). The north of Madagascar is a peculiar oceanographic area where the Indian Ocean cross-equatorial flow supplies the coastal upwelling regimes off

210 Somalia and Arabia at 5-20 $\mathrm{N}$ during June-September and open ocean upwelling at $3-12^{\circ} \mathrm{S}$ through 211 subsurface northward water flow (i.e. East African Coastal Current), while the Northeast 
212 Madagascar Current originating from the South Equatorial Current supplies water for the

213 Mozambique Channel flow (Schott et al. 2009). The NMC has been shown to be characterized by a

214 large anticyclonic gyre within the Comoros basin and a variable current flowing south-eastward in

215 the central part of the Mozambique Channel (Donguy and Piton 1991; Schouten et al. 2005).

217 In the mid-1990s, the advent of satellite altimetry revealed that the ocean circulation in the NMC is

218 predominated by Rossby wave forcing which results in the annual occurrence of several large

219 eddies of diameter 300-350 km that propagate southward through the Channel (de Ruijter et al.

220 2002; Schouten et al. 2003). Recent analysis of the mesoscale activity within the Comoros Basin

221 combining satellite altimetry data with a high-resolution ocean circulation model confirmed that the

222 anticyclonic eddies are mainly generated west of the northern tip of Madagascar due to barotropic

223 instabilities (Collins et al. 2014). Most of these anticyclonic eddies eddies propagate west across the

224 basin in about 1 month and move south into the Mozambique Channel about 3 months later (Fig. 2).

225 Some cyclonic eddies likely generated from baroclinic instability are also generated within the

226 Comoros Basin, mainly along the Northwest coast of Madagascar (Collins et al. 2014). Mesoscale

227 and sub-mesoscale oceanographic features have been shown to result in enrichment processes

228 through localized upwelling of deeper nutrient-rich waters as well as entrainment of high Chl-a

229 concentration coastal waters by the eddies in their southward progression (Tew-Kai and Marsac

230 2009; Roberts et al. 2014). In addition, eddies rotation as well as eddy-eddy interactions were found

231 to affect both the occurrence and pattern of aggregation of micronekton (Sabarros et al. 2009;

232 Béhagle et al. 2014). Such mechanisms of exchange between the shelf and open water have been

233 suggested to support the production of micronekton organisms, i.e. small fish, cephalopods, and

234 crustaceans which are the main prey of tuna (Roger 1994; Ménard et al. 2014) and other top

235 predators such as seabirds (Weimerskirch et al. 2004), whale sharks (Sequeira et al. 2012), and

236 cetaceans (Laran et al. 2017). The seasonal NMC productivity appears strongly dependent on 
mesoscale activity which has been shown to intensify during the 1990s-2000s and to be affected by

238 large-scale Indian Ocean variability (Palastanga et al. 2006; Backeberg et al. 2012).

\section{The fisheries}

241 National coastal fisheries

242 Statistical data available at IOTC indicate that the artisanal fisheries of Comoros, Mayotte,

243 Madagascar, Mozambique, and Tanzania annually caught about $20000 \mathrm{mt}$ of tuna and tuna-like 244 species within the NMC during 2012-2016. These fisheries are confined to nearshore coastal areas 245 and comprised of thousands of small motorized and non-motorized boats $(<15 \mathrm{~m})$ that use a large 246 diversity of fishing gears, including trolling, hand lines, longlines, small purse seine, and manually 247 handled small-scale drift gillnets (De Young 2006; Mutombene et al. 2017; Toihir 2017). Projects of 248 deployments of anchored Fish Aggregating Devices (FADs) have been conducted throughout the 249 1980s in the five countries bordering the NMC to support the development of artisanal fisheries 250 (Venkatasami 1990). Within Comorian and Mayotte waters, a few dozen of FADs have been 251 moored and maintained since the late 1980s at a distance of 2-5 nm from the shore where they 252 attract tuna and other pelagic fishes that are generally fished with hooks and lines by motorized 253 boats (Doherty et al. 2015; Soilihi 2017). The maintenance of anchored FADs experimentally 254 deployed in Madagascar, Mozambique and Tanzania have been less successful due to their quick 255 loss and absence of maintenance, and their overall contribution to the artisanal catch might be 256 negligible in these countries (Richmond and Mohamed 2006; Cofrepêche 2013).

258 Overall, data reported to the IOTC for the NMC artisanal fisheries are considered to be incomplete 259 and highly uncertain in absence of proper monitoring systems (Fiorellato et al. 2018). In the case of 260 Madagascar for instance, artisanal catches are not provided to the Secretariat and assumed constant 
261 from one year to the next. Total catch estimates for these fisheries suggest an increasing trend from

262 the 1970s to the mid-1990s followed by a decline until the late 2000s (Fig. 3). Total tuna catch

263 might have sharply increased in recent years due to a major increase in the skipjack catch by

264 Comorian domestic fisheries although the reasons for this remain unclear and might be due to the

265 recent change in the data management system (Toihir 2017). Over the last decade, Comoros

266 accounted for $46 \%$ of the total artisanal catch reported within the NMC, followed by Tanzania

267 ( 28\%) and Madagascar (17\%) while Mayotte and Mozambique would have represented together

268 less than $10 \%$ of the total catch. The small contribution of Mozambique to the tuna and tuna-like

269 catch in the NMC seems mainly explained by the low targeting of tuna by most Mozambican

270 coastal fisheries (Moreno 2013; Mutombene et al. 2017).

272 Tropical tunas account for about $50 \%$ of the annual reported artisanal catch within the NMC, i.e.

$27310000 \mathrm{mt}$ during 2012-2016, with skipack and yellowfin being equally represented and bigeye

274 almost absent from the catch. The remaining of the artisanal catch during 2012-2016 was composed

275 of sharks reported as an aggregate category (21\%), Spanish mackerels (13\%), neritic tunas (8\%),

276 and billfishes (8\%) (Fig. 3). In addition to the major uncertainties on the magnitude and

277 composition of the catch, there is a general lack of knowledge on the ex-vessel fish price required

278 for estimating the value of artisanal fisheries. Tuna catches from both commercial and recreational

279 coastal fisheries are sold fresh, essentially consumed locally and contribute substantially to the

280 protein supply to national populations as well as to their economy through a network of suppliers,

281 processors and traders (Moreno 2013; Soilihi 2017).

283 Overall, the poor monitoring of the national fisheries within the NMC may result in some 284 substantial under-reporting of the tuna catch of both total amounts and species and size 285 composition. More generally, this under reporting may understate the importance of these resources 
286 for the livelihood, welfare, and food security of the NMC coastal populations (Teh et al. 2011; Le 287 Manach et al. 2012; Barnes-Mauthe et al. 2013).

Foreign high seas fisheries

290 Foreign high seas fishing vessels have operated within the Mozambique Channel since the 291 expansion of the Japanese longline fishery across the Indian ocean in the mid-1950s (Geehan et al. 292 2016). Following the adoption of UNCLOS, the coastal States of the NMC established a 200-nm 293 EEZ and licensing systems were developed to grant access to foreign vessels to the national waters 294 of Comoros, Mozambique, Mayotte (France), Tanzania, and Madagascar (Tahindro 2004). Over the 295 last six decades, longline fisheries within the NMC showed a high interannual variability (Fig. 4a) 296 which may be related to several factors such as fishing access and effort allocation, as well as 297 variation in environmental conditions and tuna availability. A maximum of about $14000 \mathrm{mt}$ of 298 tropical tuna was annually caught in the late 1960s while no catch was observed in some years 299 during 1955-2016 (Fig. 4a). It is noteworthy that tropical tuna represented on average 60\% of the 300 total longline catch, which also included albacore tuna (Thunnus alalunga), billfishes, and sharks. 301 Yellowfin represented the bulk of the longline catch but showed a decreasing trend over time, 302 representing more than $80 \%$ of the tropical tuna catch in the 1950 s and less than $50 \%$ in recent 303 years. Concurrently, the relative importance of bigeye in the tropical tuna catch increased over time, 304 from less than $20 \%$ prior to the 1970 s to about $50 \%$ in recent years. The increased contribution of 305 bigeye in longline catch over time is mainly explained by the increased targeting of this species in relation with the development and global expansion of deep longline from the early 1970s (Miyake et al. 2010). Conducting longline operations at a range of 250-300 $\mathrm{m}$ and deeper was made possible by increasing the number of branchlines between floats (Ward and Hindmarsh 2007). 
310 During 2012-2016, longliners from Chinese Taipei, China, Korea, Japan, and Seychelles annually

311 caught about $2500 \mathrm{mt}$ of large yellowfin and bigeye tuna within the NMC, mainly during

312 November-March (Fig. 5). This catch might be under-reported because of illegal fishing by some

313 longliners as the national systems of monitoring, control, and surveillance are poorly operational

314 (Le Manach et al. 2012). Overall, the NMC is a seasonally important fishing ground for the Indian

315 Ocean longline fishery, accounting for about $8 \%$ of the tropical tuna longline catch over the last

316 decade, and more than 20\% in 2015. Tuna caught and retained by high seas longliners is frozen

317 onboard the vessels at about $-40^{\circ} \mathrm{C}$ or lower and exported to the Japanese high-value sashimi market

318 (Miyake et al. 2010). Estimates of total annual value of bigeye and yellowfin based on Japanese

319 import prices and average catch over the last decade varied between a minimum of about 5 million

320 USD in 2011 and a maximum of $>80$ million USD in 2007, with an annual average value $>54$

321 million USD. It is noteworthy that the uncertainty on longline catch is high due to the coarse level

322 of the public-domain data available at IOTC, resulting in large uncertainties associated with the

323 catch and associated value (Fig. 3a).

325 The NMC is also a major seasonal fishing ground for purse seine fishing since the mid-1980s and 326 the EU bilateral Fisheries Partnership Agreements (FPA) were developed to access the national 327 waters of Madagascar, Comoros, and Mozambique. It is noteworthy that the protocols for 328 Mozambique, Comoros, and Madagascar expired in January 2015, December 2016, and December 329 2018, respectively, and have not been renewed in 2019. For Tanzania, private agreements have been 330 made with purse seine fishing companies although this information is not publicly available. The 331 FPA protocols set out the period, number of vessels by gear type that can access the national waters 332 of each country, the fishing opportunities, and the financial contribution provided by the EU. 333 During the most recent period of bilateral agreements, the annual contribution of the EU tuna 334 agreements was 980000 Euros for Mozambique during 2012-2015, 600000 Euros for Comoros 
335 during 2014-2016 and about 1.5 million Euros for Madagascar during 2015-2018 (Table 3). About

336 half of the total amount was devoted to the support of the national fisheries sectors, e.g. 337 development of capacity for the monitoring, control, and surveillance of fishing activities. Over the

338 last decade, annual purse seine catch varied around $27000 \mathrm{mt}$, with a minimum of about $2000 \mathrm{mt}$ in 3392014 and more than $40000 \mathrm{mt}$ in 2009 (Fig. 4b). This illustrates the massive variations in tuna 340 availability in the region which may stem from a combination of variability in environmental 341 conditions, fishing access and catchability. The seasonality of high seas fisheries within the NMC 342 described by the average monthly catch of tropical tuna during the period 2007-2016 showed that 343 the purse seine fleet essentially operates within the NMC during the inter-monsoon period of 344 March-April (Fig. 5).

Tuna catch associated with drifting floating objects represented more than $80 \%$ of the purse seine catch over the decade 2007-2016. Tuna caught with purse seine within the NMC are generally small. The median size of skipjack, yellowfin, and bigeye caught in association with floating objects was $47 \mathrm{~cm}(2.3 \mathrm{~kg}), 56 \mathrm{~cm}(3.8 \mathrm{~kg})$ and $54 \mathrm{~cm}(3.7 \mathrm{~kg})$, respectively. Interestingly, the Mozambique Channel is a peculiar area where many logs discharged from the rivers of the coastal countries drift in the surface waters and aggregate tunas. During 2010-2013, these natural objects represented about $1 / 3$ of the floating objects used by the purse seine fishery while the remaining objects were artificial bamboo rafts deployed at sea (Maufroy et al. 2017). Over the last decade, skipjack represented about $2 / 3$ of the catch and yellowfin less than $30 \%$, with bigeye composing the rest. Compared to other fishing grounds of the western Indian Ocean, the NMC is described by a higher proportion of skipjack and smaller proportion of yellowfin in the purse seine catch on floating objects. During 2007-2016, the yellowfin proportion increased but less than in the other areas. Within the NMC, the mean annual proportion of yellowfin in purse seine catch on floating 
objects increased to about $34 \%$ during $2012-2015$ while it was more than $40 \%$ in the rest of the

360 western Indian Ocean during the same period.

362 Using Bangkok import prices as a proxy, the total annual value of the purse seine catch within the

363 NMC during the last decade was estimated to vary around 40 million USD, between a minimum of 364 less than 3 million USD in 2014 and a maximum of about 60 million USD in 2012-2013.

Synthesis

Despite their uncertainty, official fisheries statistics indicate that $>30000 \mathrm{mt}$ of tropical tuna were annually caught within the NMC in recent years, with about one third of this catch being taken by national coastal fisheries for local consumption, while the rest was harvested by foreign hish seas fleets to mainly supply the low value, high volume, cannery-grade markets of the EU ( 200000 mt $\mathrm{y}^{-1}$ caught with purse seine) and the high value, low volume, sashimi-grade market of Japan ( 2,500

$372 \mathrm{mt} \mathrm{y}^{-1}$ caught with longline). Based on available tuna prices, the total tuna catch from the high seas 373 fisheries would reach an annual value of about 100 million USD over the last decade, although 374 large uncertainties surround this estimate due to the aggregated dimension of IOTC public-domain 375 data. The magnitude of annual catch appears to be highly variable due to tuna availability affected 376 by both environmental variability and accessibility, supporting the interest of multi-annual 377 agreements with minimum reference catch volumes to ensure stable incomes to the countries, as 378 well as additional interest in good years. With the exception of Mayotte, the coastal countries 379 bordering the NMC, namely Comoros, Madagascar, Mozambique, and Tanzania, currently lack proper monitoring and compliance systems for both their coastal fisheries and the high seas foreign fleets accessing their national waters. This strongly affects the data provided to IOTC for tuna fisheries management (Fiorellato et al. 2018) but also the ability of the countries to negotiate fishing agreements in the area (Gagern and van den Bergh 2013). 


\section{Biology and ecology of Indian Ocean tropical tunas}

\section{Population structure}

387 The IOTC currently considers that skipjack, yellowfin, and bigeye consist of single panmictic

388 spawning populations at the scale of the Indian Ocean. Some studies using classical genetic markers

389 (i.e. mitochondrial DNA and DNA microsatellites) suggested that the three species might display a

390 high degree of differentiation at small geographic scales (Dammannagoda et al. 2008, 2011;

391 Menezes et al. 2012; Kunal et al. 2013; Suman et al. 2013). These results however appear to be

392 inconsistent with the lower degree of differentiation observed at much broader scales (Ely et al.

393 2005; Pecoraro et al. 2018) and the long-distance movements observed from mark-recapture data

394 collected throughout the IOTTP (section Movements \& Migrations). The identification of apparent

395 fine-scale isolated populations of tuna might be explained by the small number of molecular

396 markers used and their limited resolution to deal with the high migration rates and large population

397 sizes that characterize tuna populations. Alternative approaches based on more powerful genomic 398 approaches that rely on the advent of Next Generation Sequencing (Davey et al. 2011) technology 399 have been recently advocated as a promising tool to separate neutral evolutionary processes (i.e., 400 genetic drift) from those influenced by selection (i.e., involved in adaptive divergence) in high 401 gene-flow species such as tunas (Kolody et al. 2013; Grewe et al. 2015; Pecoraro et al. 2016). 402 Based on about 1000 co-dominant single nucleotide polymorphism markers identified with a Next 403 Generation Sequencing method, Pecoraro et al. (2018) did not detect any population structure in 404 yellowfin sampled in different locations of the western Indian Ocean. Overall, information currently 405 available from genetic studies supports the assumption that tropical tunas occurring within the 406 NMC belong to single species-specific stocks that are well mixed across the western Indian Ocean. 
409 Skipjack, yellowfin, and bigeye tunas are highly mobile species that occupy vast pelagic habitats

410 extending across entire ocean basins and make extensive migrations (Block et al. 2011; Schaefer et

411 al. 2015). These species swim quickly and continuously, day and night, and are characterized by

412 high swimming performance supported by several physiological and morphological adaptations,

413 including extended pectoral fins providing hydrodynamic lift, high metabolic capacity, and presence

414 of a gas bladder in yellowfin and bigeye (Magnuson 1978; Dewar and Graham 1994). Results from

415 experiments in the wild and in captivity have shown that tropical tunas can swim at sustained

416 speeds of 4-6 knots and burst speeds up to 13-14 knots (Yuen 1966; Magnuson 1973). A model of

417 swimming speeds for maintaining hydrostatic equilibrium for tropical tunas of $50 \mathrm{~cm}$ length

418 accounting for lifting area gives speeds of about 70, 50 and $35 \mathrm{~cm} \mathrm{~s}^{-1}$ for skipjack, yellowfin and

419 bigeye, respectively (Magnuson 1973). The model also shows that yellowfin and bigeye at larger

420 sizes can swim at slower speeds than their smaller counterparts to counter their weight in water as

421 their lifting areas increase more quickly than their weight (Magnuson 1973).

422

423 At large scales, information collected from mark-recapture studies in the Pacific, Atlantic, and

424 Indian oceans over the last decades indicates average monthly distances travelled of 600-950 nm

425 with major differences between species and oceanic regions (Fonteneau and Hallier 2015). In the

426 Indian Ocean, more than 160000 tropical tunas were tagged throughout the IOTTP operations

427 conducted during 2005-2007, among which 34000 were tagged within the NMC (Murua et al.

428 2015). Although most tags were recovered with purse seine in the Somali basin due to the spatio-

429 temporal dynamics of the fishery (Kaplan et al. 2014; Davies et al. 2014), observations of all

430 recovery positions show large-scale movements across the Indian Ocean (Fig. 6). The main tagging

431 area along the coast of Tanzania was described as a 'tuna-hub' following the quick movements of

432 the tunas outside the area and the general extent of the dispersal (Hallier and Fonteneau 2015). 
433 Tropical tunas were found to travel distances within one month that exceeded the radius of the

434 NMC area of about $350 \mathrm{~nm}$. About 2100 yellowfin, 1600 skipjack, and 900 bigeye tagged within

435 the NMC were recovered with different gears in both artisanal (hand line, gillnet, troll line) and

436 industrial (purse seine, longline) fisheries during 2005-2013. The apparent distance travelled

437 between tagging and recovery positions for these fish suggests a quick dispersal from the tagging

438 area after release, with median distances travelled $>1000 \mathrm{~nm}$ after 5 months at sea (Fig. 7).

439 Modelling the distance travelled as a function of species, average length between tagging and

440 recovery $\left(L_{F}\right)$, time at liberty, and month of tagging confirmed that the distance quickly increased

441 with days at sea and was $>430 \mathrm{~nm}$ after 1 month for the three tuna species (Supplementary Online

442 Materials; Fig. S1). Results also showed that the distance travelled varies with species and size. The

443 best model included a linear effect for length and an interaction between species and length,

444 explaining 38.3\% of the total variance (Supplementary Online Materials; Table S2). Bigeye was

445 found to travel significantly less than skipjack and yellowfin. Model predictions for a tuna tagged in

446 May and of size $56.9 \mathrm{~cm} L_{F}$ (i.e. average fork length observed in the data set of mark-recapture)

447 indicate that a bigeye would have travelled $608 \pm 43 \mathrm{~nm}$, a skipjack $791 \pm 34 \mathrm{~nm}$, and a yellowfin

$448828 \pm 28 \mathrm{~nm}$ after 60 days at sea (Supplementary Online Materials; Fig. S1).

450 Recent results from pop-up satellite tags deployed on adult tunas on the east coast of Madagascar

451 and in the vicinity of Saya-de-Malha Bank and Reunion Island also showed more extensive 452 displacements in yellowfin than bigeye, with daily distances travelled observed for some 453 individuals larger than $30 \mathrm{~nm}$ (Sabarros et al. 2017). Surprisingly, larger bigeye and yellowfin were 454 found to travel less than their smaller counterparts in the IOTTP data set while the distance travelled 455 increased with size in skipjack (Supplementary Online Materials; Fig. S2). This may be explained 456 by the hydrostatic equilibrium requirement of continuous swimming whereby larger yellowfin and 457 bigeye $(>50 \mathrm{~cm})$ can have slower swimming speeds thanks to the extensive development of their 
458 lifting area and gas bladder while the swimming speed required to maintain hydrostatic equilibrium

459 in skipjack continuously increases with size (Magnuson 1973).

461 A full mixing of the tagged fish with the untagged population is necessary to ensure that tagged 462 individuals are equally vulnerable to recapture and might result in bias in tag-based abundance 463 estimates if the assumption is not met (Hoenig et al. 1998). Despite observations of large active 464 displacements, analyses of tuna tag dynamics conducted at the scale of the ocean basin also 465 revealed some evidence for incomplete mixing of the tags within each population following release 466 (Langley and Million 2012; Kolody and Hoyle 2013). Consequently, tags with a duration at sea of 467 less than 9, 12, and 6-12 months for yellowfin, bigeye, and skipjack respectively, were removed 468 from the most recent stock assessment models to allow for a sufficiently good mixing of the tags 469 within the large areas used in the models (Langley 2015, 2016a; Fu and Fiorellato 2017). Within the 470 NMC, a few tunas tagged $(n=16)$ were found to remain within the area after 1 month, indicating 471 some potential but limited residency. The reasons for some tuna restricted displacements within the 472 NMC are unknown and could be addressed in the future by collecting information on both the 473 environment and the physiology of fish with archival tags equipped with sensors measuring internal 474 features such as temperature, $\mathrm{pH}$, and fat contents (Whitlock et al. 2015).

476 Information available from the few pop-up tags deployed in the western Indian Ocean illustrates 477 some site fidelity, with some tunas showing very limited movements for periods $>50$ days (Sabarros 478 et al. 2017). Based on the IOTTP data set, current assessment models for bigeye and yellowfin 479 estimate seasonal, constant, stage-dependent movements between areas assumed to characterize 480 different oceanographic features and the spatio-temporal patterns of the fisheries. Estimates of 481 population parameters derived through the assessments of the status of yellowfin and bigeye 482 indicate large-scale movements between areas with quarterly displacements inside and outside the 
area comprising the Mozambique Channel, although there is some large uncertainty associated with

484 these results (Langley 2015, 2016a). Although some movements across the western Indian Ocean

485 are expected for skipjack (see above), the non-availability of spatial abundance indices due to the

486 difficulties of analysing and interpreting catch rates of purse seiners and pole and liners currently

487 prevents considering spatial stratification in the assessment (Fu and Fiorellato 2017). Recent

488 progress in the standardisation of purse seine catch rates and future work focusing on the

489 development of spatial mark-recapture models might provide a better way of including the spatial

490 dimension of tuna demography into scientific advice.

492 In addition and despite evidence of massive swimming speeds and active movements, preliminary 493 modelling predictions of bigeye recaptures on a small spatial grid ( $2^{\circ} \times 2^{\circ}$ squares) using ocean 494 current flows appeared to yield promising results that could explain the observed retention of tags in 495 the western equatorial area of the Indian Ocean (Langley 2013). This approach makes the strong 496 assumption that the movements of juveniles of bigeye are essentially driven by currents, likely 497 because they are closely associated with floating objects that drift passively in near-surface currents. 498 Preliminary results suggest the major role of ocean circulation in tuna movements along the east 499 African coasts and some passive movements of skipjack and juveniles of yellowfin and bigeye that 500 might occur in association with the floating objects drifting within the fast East African Coastal and 501 Somali Currents towards the north, and Mozambique Channel eddies towards the south. Tuna 502 movements are however a combination of both active and passive components and ecosystem models have recently been developed to better capture the complex dynamics of these movements 504 by linking them to some indices of habitat suitability that depend on water temperature, food 505 availability, oxygen, and light (Dueri and Maury 2010; Dueri et al. 2014). 
507 Floating objects have been suspected for some time to play a role in the detection of biologically-

508 rich waters in the pelagic realm and could therefore influence tuna movements (Hall 1992). Our

509 understanding of the processes driving schooling and associative behaviours in oceanic fishes

510 remains however limited (Fréon and Dagorn 2000; Castro et al. 2002). Experiments at sea with

511 acoustic tags show that the fusion and fission processes driving the grouping of tropical tunas are

512 highly dynamic in space, depth, and time, resulting in unpredictable times of residency with drifting

513 FADs (Govinden et al. 2010; Schaefer and Fuller 2013; Matsumoto et al. 2014; Lopez et al. 2017).

514 Such fast dynamics of school formation were also observed during the IOTTP tagging operations

515 characterized by a high turn-over rate of tunas joining and leaving the school associated with the

516 pole and liners (Hallier and Fonteneau 2015). At large scales, the massive deployment of dFADs in

517 purse seine fisheries has been suggested to modify the movements of tropical tunas (Hallier and

518 Gaertner 2008; Wang et al. 2014). Although further studies are required to improve our

519 understanding of the relationships between abundance, schooling, and movements in gregarious

520 fish, recent reviews of the mechanisms driving the dynamics of aggregations point out how

521 individual interactions could play a key role in stabilizing tuna populations (Rieucau et al. 2015;

522 Maury 2017).

\section{Growth}

525 Growth is an essential parameter for assessing tuna populations as their reproduction, mortality, and

526 movements are age-dependent (Hampton 2000). Observations of maximum size of the three tropical

527 tunas in the wild illustrate the major differences in life history traits between small-sized skipjack

528 described by a maximum fork length of about $100 \mathrm{~cm}$ and maximum round weight of about $30 \mathrm{~kg}$,

529 and larger-sized yellowfin and bigeye that can reach $200 \mathrm{~cm}$ (i.e. $\sim 165 \mathrm{~kg}$ ) and $206 \mathrm{~cm}$ (i.e. 207

$530 \mathrm{~kg}$ ), respectively (Table 2). In the absence of fishing, skipjack could live up to 7 years and the

531 longevity of yellowfin and bigeye would be 9 and 15 years, respectively (Table 2). Tuna growth has 
532 been the focus of a large number of studies since the early 1950s (Murua et al. 2017). Overall, the

533 growth of tropical tunas raises several issues that are linked to: (i) the difficulty of sampling large

534 populations distributed in extensive habitats and caught with selective fishing gears, (ii) the high

535 individual variability in growth exacerbated by high genetic variability and habitat extent, (iii) the

536 limited detection of clear annual signals in calcified structures such as otoliths, and (iv) the tracking

537 of population cohorts through modal progression analysis when tropical tunas spawn all year round.

538 Three principal data sources are available for studying the growth of Indian Ocean bigeye, skipjack,

539 and yellowfin tunas. First, a large data set of increased individual fish lengths over known times-at-

540 liberty has been collected as part of the IOTTP (Murua et al. 2015). Second, direct ageing from

541 daily increments deposited in sagittal otoliths was conducted for about 500 tropical tunas collected

542 during the IOTTP (Sardenne et al. 2015). Micro-increments appeared however difficult to read in

543 skipjack and adult bigeye $(>100 \mathrm{~cm})$ resulting in uncertainties in the interpretation of otolith micro-

544 structural features (Williams et al. 2013; Sardenne et al. 2015). Third, modal progression in length-

545 frequency distributions obtained from the purse seine fishery catches was used to track the

546 population cohorts over months and provide both mean age and length estimates of yellowfin and

547 bigeye populations during their juvenile phase (Dortel et al. 2012). Gear selectivity might however

548 affect estimates obtained from modal progression through individual size-specific selection (Kolody

549 et al. 2016).

550

551 Integrated parametric growth models developed and fitted to the different growth data sources and

552 accounting for individual variability support a complex growth curve characterized by two stanzas

553 for all three tuna species (Dortel et al. 2015; Eveson et al. 2015). The three tropical tunas have

554 different growth patterns over their lifespan in the Indian Ocean (Fig. 8). Skipjack appear to

555 experience fast growth until 45-50 cm (i.e. 8-13 months old) followed by slower growth in larger

556 fish. This pattern might be linked to a change in energy allocation and trade-off with reproduction 
investment since the length at which $50 \%$ of the females are mature is $40 \mathrm{~cm}$ (section Reproduction

558 section for more details). By contrast, the growth curve for yellowfin suggests they experience

559 slower growth as juveniles, followed by rapid growth from around $70 \mathrm{~cm}$ (Fig. 8). A similar but less

560 marked pattern is observed for bigeye (Eveson et al. 2015). Ontogenetic changes in physiological

561 and anatomical features combined with habitat expansion that would reduce intra- and inter-specific

562 competition within schools has been put forward to explain the two-stanza growth in yellowfin

563 (Dortel et al. 2015; Maury 2017). Values of the growth parameter estimated in the first phase show

564 the differences in life history traits with skipjack described by faster growth $\left(\mathrm{K}_{1}=1.41 \mathrm{y}^{-1}\right)$ than

565 yellowfin $\left(\mathrm{K}_{1}=0.21 \mathrm{y}^{-1}\right)$ and bigeye $\left(\mathrm{K} 1=0.06 \mathrm{y}^{-1}\right)$ tuna (Table 2). In addition, information

566 collected on the sex of tagged yellowfin and bigeye at recovery showed a strong sexual dimorphism

567 in growth for these two species, with old yellowfin males growing about $10 \mathrm{~cm}$ larger than females

568 (Eveson et al. 2015).

570 For a given size in the range $44-60 \mathrm{~cm}$, skipjack grow much slower than yellowfin and bigeye.

571 Observations of raw individual growth rates derived from tunas tagged within the NMC for similar 572 sizes show median values of $0.66 \pm 0.14 \mathrm{~cm} \mathrm{mo}^{-1} \mathrm{~cm}$ for skipjack while bigeye and yellowfin 573 display significantly higher median growth rates of $1.55 \pm 0.26 \mathrm{~cm} \mathrm{mo}^{-1}$ and $1.29 \pm 0.15 \mathrm{~cm} \mathrm{mo}^{-1}$,

574 respectively (Fig. 9). Modelling the mean growth rates with generalized additive models that 575 account for both month of tagging and duration at liberty supports the assumption that juveniles of 576 yellowfin and bigeye grow faster than skipjack of similar sizes in the NMC. The best model 577 explained more than $45 \%$ of the variance and showed species-specific differences in growth 578 patterns as indicated by the significant interaction effect between length and species 579 (Supplementary Online Materials; Table S2). Model predictions for tunas tagged within the NMC 580 during the month of May show an increasing trend in growth rate for bigeye over the size range 581 observed between tagging and recovery, i.e. 37-78 cm. Growth rates of juveniles of bigeye increase 
582 from about $1 \mathrm{~cm} \mathrm{mo}^{-1}$ at $45 \mathrm{~cm}$ to $>2 \mathrm{~cm} \mathrm{mo}^{-1}$ at $60 \mathrm{~cm} \mathrm{~L}_{F}$ (Supplementary Online Materials; Fig.

583 S3). By contrast, juveniles of yellowfin show a decreasing trend with mean growth rates varying

584 from about $1.4 \mathrm{~cm} \mathrm{mo}^{-1}$ at about $45 \mathrm{~cm}$ to about $1.1 \mathrm{~cm} \mathrm{mo}^{-1}$ at $60 \mathrm{~cm} \mathrm{~L}_{F}$ (Supplementary Online

585 Materials; Fig. S3). The lower growth rates of skipjack compared to yellowfin and bigeye are also

586 shown, and decrease from about $0.86 \mathrm{~cm} \mathrm{mo}^{-1}$ at $45 \mathrm{~cm}$ to a minimum of $0.55 \mathrm{~cm} \mathrm{mo}^{-1}$ at about 52

$587 \mathrm{~cm} L_{F}$, followed by an increase to about $0.9 \mathrm{~cm} \mathrm{mo}^{-1}$ at $60 \mathrm{~cm} L_{F}$ (Supplementary Online Materials;

588 Fig. S3). Overall, information derived from mark-recapture data shows distinct growth patterns

589 between tropical tunas when they occur within the NMC, with bigeye and yellowfin being

590 described by concave up and concave down curves during their juvenile phase, respectively. Also,

591 although growth is assumed to be very fast in their early-juvenile phase $(<30 \mathrm{~cm})$, there is currently

592 a lack of information on the growth of tropical tunas in the wild before their recruitment to the

593 fisheries. Information collected on micro-increments deposited in calcified structures such as

594 otoliths would be useful to better understand the dynamics of growth in larvae and early juveniles of

595 tropical tunas which determine the timing of arrival in the purse seine fishery (Campana and

596 Neilson 1985). Finally, the development of full-life cycle models built on physiological and

597 metabolic theoretical grounds appears necessary to establish the mechanistic links between

598 physiology, biology (e.g. growth, reproduction) and environmental conditions (i.e. prey availability

599 and oceanographic parameters) in order to assess the spatio-temporal variability in tuna growth and

600 eventually quantify the role of each biogeographic province such as the NMC in supporting Indian

601 Ocean tuna populations (Dueri and Maury 2010).

602

603 Reproduction

604 Tropical tunas are iteroparous species characterized by indeterminate fecundity, asynchronous 605 oocyte development, protracted spawning periods, and multiple batch spawning (Schaefer 2001; 606 Juan-Jordá et al. 2013). Estimating the reproductive potential of multiple batch spawners requires 
607 knowledge of the sex ratio, spawning frequency, i.e. the mean spawning interval between sequential

608 spawning events, and batch fecundity, i.e. the number of eggs produced per spawning (McBride et

609 al. 2015). Obtaining a representative sample of the spawning female population is difficult in the

610 wild as tunas spawn in surface waters principally at night and fish collection can be biased by the

611 selectivity of sampling gears, i.e. timing of fishing, size selection, and water column depth (Itano

612 2000; Schaefer 2001). Spawning frequency can be derived from females containing hydrated

613 oocytes or from females containing postovulatory follicles of known age through ovarian histology

614 (Hunter and Macewicz 1985). Sampling tuna females containing hydrated oocytes is however

615 generally difficult due to the short duration of the hydration process and general lack of operations

616 at night of surface fishing gears (Schaefer 2001). Degenerating postovulatory follicles can be used

617 for estimating spawning frequency as they have been shown to remain up to 24 hours in the ovary

618 after ovulation in tropical tunas (Hunter et al. 1986; McPherson 1991; Schaefer et al. 2005).

620 In the Indian Ocean, a large set of information has been collected on spawning period, sex ratio, 621 maturity, and batch fecundity for yellowfin and skipjack tunas since the mid-1970s (Stéquert 1976; 622 Hassani and Stéquert 1991; Stéquert and Ramcharrun 1995, 1996; Stéquert et al. 2001; Zudaire et 623 al. 2013; Grande et al. 2014). By contrast, little information is currently available for bigeye tuna 624 (Zudaire et al. 2016). Knowledge acquired on the reproduction of Indian Ocean tropical tuna is not 625 specific to the NMC although some samples used for analysing the reproductive traits originate 626 from the area (Zudaire et al. 2013, 2016b; Grande et al. 2014). Temporal changes in the gonado627 somatic index combined with histological interpretation of preserved ovarian material and variation 628 in steroid hormones show that yellowfin and bigeye have a major peak of spawning along the 629 Seychelles-Chagos thermocline ridge during the months of November-March, i.e. the Northwest 630 monsoon season (Hassani and Stéquert 1991; Stéquert et al. 2001; Zudaire et al. 2013, 2016). A 631 second less-marked peak was observed during the Southeast monsoon in June-August (Zudaire et 
632 al. 2013). Histological analysis also indicated that large mature yellowfin females have a longer

633 spawning period than the smaller mature ones (Zudaire et al. 2013). By contrast, skipjack spawn all

634 year round although the reproductive activity may be lower during inter-monsoon periods (Stéquert

635 1976; Stéquert et al. 2001; Grande et al. 2014).

636

637 Tropical tunas are mostly recruited into the purse seine fishery $(\sim 30 \mathrm{~cm})$ before they reach their first 638 maturity. The reproductive traits of the 3 species show a marked gradient, from skipjack tuna 639 characterized by early maturation at around 7 months $\left(L_{F} \sim 40 \mathrm{~cm}\right)$ and high relative batch fecundity 640 of about $136 \pm 66$ eggs $\mathrm{g}^{-1}$ body weight, to yellowfin and bigeye described by later maturity at 641 around 2.3 years $\left(L_{F} \sim 75 \mathrm{~cm}\right)$ and 3 years $\left(L_{F} \sim 100 \mathrm{~cm}\right)$, respectively, and lower fecundity at about $64276 \pm 40$ eggs $g^{-1}$ and $10 \pm 7$ eggs g $^{-1}$, respectively (Table 2). Maximum values of batch fecundity 643 increase with tuna size in the three tropical tunas as shown by the increasing trends in the $75 \%$ non644 linear quantile regression models between batch fecundity and fish standardized fork length (Fig. 645 10). The increasing maximum levels of fecundity with size appear to be mainly explained by the 646 increasing weight of gonads with fish size (Fig. 11). The high variability in fecundity observed 647 between individuals of similar size indicates that some other factors than size affect the fecundity, 648 and hence the reproductive potential of tropical tunas in the Indian Ocean. The number of eggs 649 released might depend on recently acquired energy since the three species utilize food resources 650 throughout the spawning season (i.e. income breeding strategy). The large variability observed in 651 fecundity might then reflect differences in feeding success prior to and during spawning. In 652 addition, the variability in fecundity between successive batches is poorly known while the potential 653 existence of some fish that may skip spawning due to insufficient energy for initiating oocyte 654 development has been suggested but it is difficult to demonstrate in tropical tunas (Zudaire et al. 655 2013). 
657 Spawning frequency for the 3 species could not be determined in the Indian Ocean due to the 658 absence of postovulatory follicles in most tunas sampled while data from the Pacific indicate a 659 frequency close to daily, i.e. 1.1-1.2 days in skipjack (Hunter et al. 1986), 1.1-2 days in yellowfin, 660 and 1.4-1.6 in bigeye tuna (McPherson 1991; Schaefer 1996; Itano 2000; Sun et al. 2013). Overall, 661 the reproductive potential of the 3 species remains poorly known due to the absence of better 662 information on spawning frequency and improved understanding of regulation mechanisms in tunas 663 in relation with poor-feeding environment such as skipped spawning, delayed maturation, and fewer 664 spawning events per season or fewer eggs produced per event (McBride et al. 2015).

665

666 Recent studies based on lipid classes and profiles of fatty acids that focused on the mechanisms of 667 energy allocation in yellowfin and skipjack showed the tight linkage between environmental 668 conditions and egg production (Zudaire et al. 2014, 2015; Grande et al. 2016). Skipjack are 669 described by an income breeding strategy, i.e. they use recently acquired food resources to fuel 670 reproduction, taking advantage of nutrients critical for offspring survival that are available at the 671 spawning site (Grande et al. 2016). Female yellowfin also depend on prey availability and quality at 672 the time of spawning although they are able to store part of the energy prior to the reproduction 673 period (Zudaire et al. 2014).

675 Tunas aggregate for spawning in surface waters $>24^{\circ} \mathrm{C}$ following periods of courtship behaviour 676 that have been observed for yellowfin held in captivity (Margulies et al. 2007). Experiments showed 677 that mean egg-stage duration is inversely correlated with water temperature and lasts up to a 678 maximum of 28 hours (Margulies et al. 2007). Tuna larvae usually occur in low density patches 679 near the surface, both during day and night. Historical information available from the Atlantic 680 Ocean indicates that larvae of yellowfin and bigeye might migrate to the surface during the day 681 while skipjack larvae are at the surface during the night (Richards and Simmons 1971). 
682 Ichthyoplankton surveys conducted around Hawaii during 1985-1986 however showed that

683 Thunnus spp. larvae were mostly captured in the neuston at night but rarely in daytime, with 684 skipjack larvae occurring deeper and no clear evidence of diel vertical migration (Boehlert and 685 Mundy 1994).

687 Scientific ichthyoplankton surveys conducted as early as the late 1920s in the Indian Ocean 688 indicated the occurrence of skipjack and yellowfin tuna larvae in the Mozambique Channel while 689 very few larvae of bigeye tuna were found throughout the surveys (Jones and Kumaran 1963; 690 Conand and Richards 1982; Beckley and Leis 2000). Skipjack larvae predominated in the NMC and 691 tuna larvae were the most abundant during November-April (Conand and Richards 1982; Beckley 692 and Leis 2000). Although the Mozambique Channel appears to be a relatively poor feeding habitat 693 compared to other areas of the western Indian Ocean such as the Somali basin (Druon et al. 2017), 694 the warm waters $\left(>27^{\circ} \mathrm{C}\right)$ of the area combined with mesoscale activity that enhances enrichment 695 through mixing and retention (Tew Kai and Marsac 2010) may constitute optimal environmental 696 conditions for tuna spawning (Reglero et al. 2014). New reproductive studies specifically focusing 697 on samples collected throughout the year within the NMC combined with ichthyoplankton surveys 698 would be essential to fully resolve the role of the area for tuna spawning and stocks recruitment.

Trophic ecology

701 Tunas are opportunistic predators at the apex of short food chains (Roger 1994). Tunas forage on ca. 70245 prey families, from various micronekton assemblages composed of crustaceans (mainly the 703 pelagic crab Charybdis smithii and the mantis shrimp Natosquilla investigatoris), fishes (mainly the 704 cigarfish Cubiceps pauciradiatus and Decapterus spp) and cephalopods (mainly Sthenoteuthis 705 oualaniensis) (Potier et al. 2007, 2008a; Jaquemet et al. 2011; Potier et al. 2011; Duffy et al. 2017). 706 The proportion of each prey depends on biological parameters such as vertical behaviour, ontogeny, 
reproduction, and the seasonal migration across regions described by different oceanographic

708 conditions and prey availability. Dissolved oxygen and temperature are key drivers constraining

709 tuna physiological abilities and vertical behaviour (Graham and Dickson 2004). Bigeye tuna is

710 tolerant to pronounced oxygen and temperature deficiencies, and commonly forages beyond the

711 scattering layer on mesopelagic preys such as myctophids and squid S. oualaniensis and

712 Ornithoteuthis volatilis (Potier et al. 2008a; Ménard et al. 2014). Yellowfin and skipjack tunas

713 prefer the oxygenated and warmer waters of the epipelagic layer (Graham and Dickson 2004).

714 Yellowfin tuna usually forage in the mixed layer on diverse prey species, including fish, crustaceans

715 and squid in almost equal part (Potier et al. 2004, 2007; Zudaire et al. 2015) while skipjack forage

716 in the surface layers, mainly on crustaceans (Grande 2013). Beyond the inter-specific differences,

717 vertical behaviour changes with ontogeny as tuna diving capacities develop with size (Holland et al.

718 1992). Until ca. $50 \mathrm{~cm}$, tuna’s trophic position increases with the ability to feed on bigger preys in

719 the epipelagic layer (Potier et al. 2008a; Sardenne et al. 2016). Afterwards, their trophic position

720 increases only slightly, even for bigeye and yellowfin tunas which feed more extensively on deep

721 prey when they reach 90 and 110 cm, respectively (Ménard et al. 2007; Sardenne et al. 2016).

722 Despite these differences, tropical tunas commonly form mixed chasing schools in the near surface

723 layer and in this context have a similar feeding behaviour when prey diversity is low (Potier et al.

724 2004; Fonteneau et al. 2008). As a result, food competition is strong in the near surface layer

725 between skipjack and juveniles of yellowfin tuna on FADs (Jaquemet et al. 2011; Sardenne et al.

726 2016), as well as between adult yellowfin and bigeye when occurring in free swimming schools

727 (Zudaire et al. 2015), or when tunas are attracted by a prey bloom (Fonteneau et al. 2008).

729 Although a direct link between the mesoscale eddies of the Mozambique Channel and tuna diet has

730 not yet been well established (Tew Kai and Marsac 2010; Potier et al. 2014), their trophic position

731 estimated through nitrogen stable isotopes values $\left(\delta^{15} \mathrm{~N}\right)$ is lower than in other regions, about 3\%o 
732 lower than in the rest of the western Indian Ocean (Ménard et al. 2007; Zudaire et al. 2015;

733 Sardenne et al. 2016). Shorter food chains and lower baseline values linked to the low $\delta^{15} \mathrm{~N}$ values

734 of the particulate organic matter in the Mozambique Channel were proposed to explain this

735 difference (Ménard et al. 2007; Kojadinovic et al. 2007; Lorrain et al. 2015). Recently, the

736 relationships between tuna trophic position and environmental conditions were investigated on

737 global and regional scales by adjusting for variability in baseline $\delta^{15} \mathrm{~N}$ values using a Model of

738 Ocean Biogeochemistry and Isotopes (MOBI) (Pethybridge et al. 2018). Homogeneous MOBI-

739 derived phytoplankton $\delta^{15} \mathrm{~N}$ values were obtained in the Mozambique Channel $(3.6 \pm 0.2 \%$ ) and in

740 the rest of the western Indian Ocean (3.5 $\pm 0.3 \%$ ). Hence, the lower trophic position of tropical tunas

741 in the NMC is most likely related to shorter lengths of food chains in this area compared to the

742 western Indian Ocean, i.e, tuna prey in the NMC would be about one trophic level lower that in

743 other parts of the region. Such short food chains suggest a higher sensitivity of tuna to climate

744 change through variability in baseline composition and abundance in the NMC in a context of

745 marked warming of the Mozambique Channel (Popova et al. 2016). Extended work on the spatio-

746 temporal variations of plankton biomass and stable isotope composition in the western Indian

747 Ocean, especially zooplankton, is essential to clarify tuna foraging and migrating behavior,

748 including its dependency to the NMC.

750 There is currently a lack of studies on the trophic ecology of tropical tuna larvae in the western

751 Indian Ocean which have been shown to feed on a diversity of species of microzooplankton (20-

$752200 \mu \mathrm{m})$ and to a lesser extent mesozooplakton $(0.2-20 \mathrm{~mm})$, mostly appendicularians in the case of

753 skipjack tuna (Young and Davis 1990; Llopiz et al. 2010). Recent surveys conducted in the

754 Mozambique Channel showed how mesoscale features shape the distribution of small copepods,

755 appendicularians, ostracods, and chaetognaths by increasing their abundance in cyclonic eddy-cores

756 and divergence areas between eddies (Huggett 2014; Lebourges-Dhaussy et al. 2014). Such 
processes of enrichment, concentration, and retention might explain the importance of the NMC as

758 a major spawning area for skipjack, and yellowfin to a lesser extent, consistently with the ocean

759 triad that assumes that eddy motions provide a combination of physical processes particularly

760 favorable for the reproductive habitat of pelagic fishes (Bakun 2006).

\section{Synthesis}

763 Tropical tunas are active, fast swimmers that can perform large directed displacements across the

764 Indian Ocean basin throughout the year and move inside or outside large areas such as the NMC

765 within a few days. A rough scheme of spawning and feeding migrations of tropical tunas in the

766 western Indian Ocean can be hypothesized as follows. From the southwestern monsoon (June-

767 September) to the inter-monsoon (October-November), tropical tunas forage north of the equator,

768 within the seasonal upwelling that develops along the Somali coast and in the north of the

769 Seychelles Plateau. In both areas, they feed extensively on pelagic crabs (Romanov et al. 2009;

770 Grande 2013) and mantis shrimps (Potier et al. 2002; Malone et al. 2011). During the northeast

771 monsoon (December-March), most tunas in spawning activity forage between the Chagos Islands

772 and the south of the Seychelles Plateau, mainly on small fish such as C. pauciradiatus which

773 provide rich prey for offspring (Potier et al. 2008b; Grande 2013; Zudaire et al. 2015) and are

774 supported by high copepod biomass (Roger 1994). Skipjack remaining within the Somali region

775 appear to feed mainly on pelagic mollusks and gelatinous organisms (Grande 2013). Finally, during

776 the inter-monsoon (April-May), tunas reach the NMC and adopt a more diverse diet (Grande 2013).

777 The warm waters of the NMC offer particularly favorable feeding, spawning and nursery conditions

778 for skipjack tuna. Some yellowfin individuals are suspected to permanently reside within the NMC

779 (Ménard et al. 2007; Zudaire et al. 2015). Overall, the NMC is a key feeding area for tropical tunas

780 as it sustains their high energetic needs while the ocean productivity decreases at higher latitudes

781 during the spring inter-monsoon (Burkill et al. 1993). 
783 The future of NMC tuna fisheries

\section{Ocean warming}

785 Tuna productivity within the NMC area is highly variable and strongly dependent on large-scale

786 ocean-atmosphere processes that affect the circulation in the Mozambique Channel in a context of

787 alarming warming (Popova et al. 2016). In particular, satellite altimetry data suggested that the

788 intensification of the mesoscale activity observed in the Mozambique Channel during 1993-2009

789 was due to an increase in the South Equatorial Current which was driven by enhanced trade winds

790 over the tropical Indian Ocean (Backeberg et al. 2012). The Mozambique Channel has been

791 identified as a warming hotspot and projections from a high-resolution global ocean model suggest

792 an increase of the mean sea surface temperature by $1-2^{\circ}$ by 2050 and by about $4^{\circ}$ by 2100 relative

793 to the year 2000 (Popova et al. 2016). The impact of ocean warming on tuna productivity and

794 fisheries within the NMC is extremely difficult to predict as several physical and biological

795 oceanographic processes will be affected in the future and they might modify the composition and

796 dynamics of phytoplankton and propagate up the food web to top-predators. Long-term projections

797 of tuna abundance and distribution at global scale based on environmental niche models and

798 Intergovernmental Panel on Climate Change scenarios suggest that yellowfin and skipjack might

799 become more abundant in tropical areas and in coastal areas by the 2050s (Erauskin Extramiana et

800 al. 2019). Projections from a mechanistic model accounting for both the effects of ocean warming

801 on tuna habitat and biology (i.e. growth, survival and spawning) also predict significant changes in

802 the basin-scale distribution of skipjack resulting from a reduction in habitat suitability in the

803 shallow waters of the Indian Ocean equatorial area (Dueri et al. 2014). Nevertheless, the model does

804 not seem to show any major change within the NMC (Dueri et al. 2014). Predictions of changes in

805 tuna distribution patterns should explicitly consider mesoscale and sub-mesoscale features that are 
806 key drivers of tuna occurrence within the NMC (see above). In this context, coupling eddy-

807 resolving ocean models with food web and mechanistic tuna population models in specific ocean

808 regions such as the NMC seems essential to better understand the impacts of future warming on

809 tuna fisheries in the area. This will require in particular to obtain and make accessible fine-scale

810 data sets such as the high-resolution positions of high-seas fishing vessels recently made available

811 by Global Fishing Watch (Kroodsma et al. 2018).

813 Access to fishing grounds

814 The future of the NMC tuna fisheries is also dependent on the accessibility to the fishing grounds at

815 a time when there is no ongoing fishing agreement between the EU and the coastal countries and

816 IOTC members are debating about the criteria of catch allocation (IOTC 2019). Following the

817 presidential elections in Madagascar in late 2018, the negotiation process of fisheries access

818 agreements with the EU will likely resume in 2019. The renewal of a fishing agreement between the

819 EU and Comoros might take more time as the country has been identified as non-cooperating third

820 country under the EU's regulation to fight and deter illegal, unreported and unregulated fishing.

821 Finally, the conditions imposed to the EU fishing vessels by Mozambique for accessing the national

822 waters are considered inapplicable by the fishing companies. No EU FPA has ever been developed

823 with Tanzania but some Memoranda of Understanding exist with the purse seine fishing companies

824 and EU vessels might be able to seasonally operate within the Tanzanian EEZ if an agreement is

825 found with the government. Information on fishing agreements between Asian longline fisheries

826 and the NMC coastal countries as well as data on operational costs of high seas fishing fleets would

827 be extremely useful to assess the distribution of benefits and fairness of the agreements. The

828 negotiation of both public and private fishing agreements would likely benefit from improved data

829 collection, increased transparency, and active collaboration between the NMC countries to generate

830 leverage and influence distant water fishing nations. 


\section{Conclusions}

833 The pelagic zone of the NMC offers a favourable habitat for tunas which seasonally migrate in the

834 area for both feeding and spawning, benefiting from mesoscale-driven enrichment and increased

835 prey abundance. With an annual catch of about $10000 \mathrm{mt}$ in recent years by coastal fisheries, tuna 836 and tuna-like species represent an important component of food security for the low-income 837 countries bordering the NMC, i.e. Madagascar, Mozambique, Comoros, and Tanzania. The NMC is 838 also a major tuna fishing ground for high seas fishing fleets which annually export an average catch 839 of more than $20000 \mathrm{mt}$ of about 100 million USD value to the tuna can and sashimi markets of 840 high-income countries.

842 The contribution of tuna caught by the artisanal fisheries to the welfare and economy of the least

843 developed countries bordering the NMC is poorly understood and studied. Acknowledging the lack 844 of data available to properly assess the economic dependence of Coastal States on fishery resources 845 and impacts of fishery resource rents in terms of income, investments and jobs, the IOTC recently 846 recommended a pilot study to (i) evaluate what socio-economic data are collected and available and

847 (ii) propose a suite of socio-economic indicators that would describe the respective CPCs economic 848 and social aspects of fisheries (IOTC Res. 18/09). Such information is essential for the Coastal 849 States as the economic dependence on tuna resources is one of the criteria that is under 850 consideration for tuna catch allocation (IOTC 2019). In data-poor situations, developing and 851 conducting fisher surveys to collect individual-level data on fishing practices, effort, catch, costs, 852 and revenues has been shown to be an efficient approach for assessing the socio-economic 853 importance of small-scale fisheries in the south-west of Madagascar (Barnes-Mauthe et al. 2013).

854 Some fisher surveys have been conducted in some NMC countries but they remain limited and do 855 not include any extrapolation at the national level (Ranaivoson and Ranaivoarison 2013). In the 
Seychelles where a good fisheries monitoring system is in place, a national satellite account for tuna

857

858

859

860

861

862 863

864

865

Backeberg BC, Penven P, Rouault M (2012) Impact of intensified Indian Ocean winds on mesoscale variability in the Agulhas system. Nat Clim Change. doi: 10.1038/nclimate1587

Bakun A (2006) Fronts and eddies as key structures in the habitat of marine fish larvae: opportunity, adaptive response and competitive advantage. Sci Mar 70:S2

Barnes-Mauthe M, Oleson KLL, Zafindrasilivonona B (2013) The total economic value of smallscale fisheries with a characterization of post-landing trends: An application in Madagascar with global relevance. Fish Res 147:175-185. doi: 10.1016/j.fishres.2013.05.011

Beckley LE, Leis JM (2000) Occurrence of tuna and mackerel larvae (Family: Scombridae) off the east coast of South Africa. Mar Freshw Res 51:777-782. doi: 10.1071/mf00044

Béhagle N, du Buisson L, Josse E, et al (2014) Mesoscale features and micronekton in the Mozambique Channel: An acoustic approach. Deep Sea Res Part II Top Stud Oceanogr 100:164-173. doi: 10.1016/j.dsr2.2013.10.024

Bistoquet K, Marguerite M, Lucas T, et al (2018) Development of the Fishery Satellite Account in the Seychelles. IOTC, Victoria, Seychelles, 29 October - 3 November, 2018, 7p

Block BA, Jonsen ID, Jorgensen SJ, et al (2011) Tracking apex marine predator movements in a dynamic ocean. Nature 475:86-90. doi: 10.1038/nature10082

Boehlert GW, Mundy BC (1994) Vertical and onshore-offshore distributional patterns of tuna larvae in relation to physical habitat features. Mar Ecol Prog Ser 107:1-13

Burkill PH, Mantoura RFC, Owens NJP (1993) Biogeochemical cycling in the northwestern Indian Ocean: a brief overview. Deep Sea Res Part II Top Stud Oceanogr 40:643-649. doi: 10.1016/0967-0645(93)90049-S 
Campana SE, Neilson JD (1985) Microstructure of fish otoliths. Can J Fish Aquat Sci 42:10141032. doi: $10.1139 / \mathrm{f} 85-127$

Castro JJ, Santiago JA, Santana-Ortega AT (2002) A general theory on fish aggregation to floating objects: an alternative to the meeting point hypothesis. Rev Fish Biol Fish 11:255-277

Chassot E, Assan C, Soto M, et al (2015) Statistics of the European Union and associated flags purse seine fishing fleet targeting tropical tunas in the Indian Ocean 1981-2014. In: IOTC Proceedings. CTOI, Victoria, Seychelles, 23-28 October 2015, 32p

Cofrepêche (2013) Résultats du suivi des impacts socio-économiques des dispositifs concentrateurs de poissons (DCP) ancrés sur les pêcheries côtières de la zone sud-ouest de l'océan Indien. Etude proposée au titre de la contribution française au projet des pêches du sud-ouest de l’océan Indien (SWIOFP)

Collins C, Hermes JC, Reason CJC (2014) Mesoscale activity in the Comoros Basin from satellite altimetry and a high-resolution ocean circulation model. J Geophys Res Oceans 119:47454760. doi: 10.1002/2014JC010008

Conand F, Richards WJ (1982) Distribution of tuna larvae between Madagascar and the Equator, Indian Ocean. Biol Oceanogr 1:321-336. doi: 10.1080/01965581.1982.10749446

Dammannagoda ST, Hurwood DA, Mather PB (2008) Evidence for fine geographical scale heterogeneity in gene frequencies in yellowfin tuna (Thunnus albacares) from the north Indian Ocean around Sri Lanka. Fish Res 90:147-157

Dammannagoda ST, Hurwood DA, Mather PB (2011) Genetic analysis reveals two stocks of skipjack tuna (Katsuwonus pelamis) in the northwestern Indian Ocean. Can J Fish Aquat Sci 68:210-223. doi: 10.1139/F10-136

Davey JW, Hohenlohe PA, Etter PD, et al (2011) Genome-wide genetic marker discovery and genotyping using next-generation sequencing. Nat Rev Genet 12:499-510. doi: 10.1038/nrg3012

Davies TK, Mees CC, Milner-Gulland EJ (2014) Modelling the spatial behaviour of a tropical tuna purse seine fleet. PLOS ONE 9:e114037. doi: 10.1371/journal.pone.0114037

de Ruijter WPM, Ridderinkhof H, Lutjeharms JRE, et al (2002) Observations of the flow in the Mozambique Channel. Geophys Res Lett 29:140-1. doi: 10.1029/2001GL013714

De Young C (2006) Review of the state of world marine capture fisheries management: Indian Ocean, FAO. FAO, Rome, Italy

deCastro M, Sousa MC, Santos F, et al (2016) How will Somali coastal upwelling evolve under future warming scenarios? Sci Rep 6:30137. doi: 10.1038/srep30137

Dewar H, Graham J (1994) Studies of tropical tuna swimming performance in a large water tunnel Kinematics. J Exp Biol 192:45-59

Doherty B, Herfaut J, Le Manach F, et al (2015) Reconstructing domestic marine fisheries in Mayotte from 1950-2010. In: Fisheries catch reconstructions in the Western Indian Ocean, 
1950-2010. Le Manach F and Pauly D, Fisheries Centre, University of British Colombia, pp $53-65$

Donguy J-R, Piton B (1991) The Mozambique Channel revisited. Oceanol Acta 14:549-558

Dortel E, Sardenne F, Bousquet N, et al (2015) An integrated Bayesian modeling approach for the growth of Indian Ocean yellowfin tuna. Fish Res 163:69-84. doi: 10.1016/j.fishres.2014.07.006

Dortel E, Sardenne F, Le Croizier G, et al (2012) A hierarchical Bayesian integrated model incorporating direct ageing, mark-recapture and length-frequency data for yellowfin (Thunnus albacares) and bigeye (Thunnus obesus) of the Indian Ocean. In: IOTC Proceedings. IOTC, Grand Baie, Mauritius, 24-29 October 2012, p 20p

Druon J-N, Chassot E, Murua H, Lopez J (2017) Skipjack tuna availability for purse seine fisheries is driven by suitable feeding habitat dynamics in the Atlantic and Indian Oceans. Front Mar Sci 4:. doi: 10.3389/fmars.2017.00315

Dueri S, Bopp L, Maury O (2014) Projecting the impacts of climate change on skipjack tuna abundance and spatial distribution. Glob Change Biol 20:742-753. doi: 10.1111/gcb.12460

Dueri S, Maury O (2010) Application of the APECOSM-E model to the skipjack tuna (Katsuwonus pelamis) fisheries of the Indian Ocean. In: IOTC Proceedings. IOTC, Victoria, Seychelles, 18-26 October 2010, 36p

Duffy LM, Kuhnert PM, Pethybridge HR, et al (2017) Global trophic ecology of yellowfin, bigeye, and albacore tunas: Understanding predation on micronekton communities at ocean-basin scales. Deep Sea Res Part II Top Stud Oceanogr 140:55-73. doi: 10.1016/j.dsr2.2017.03.003

Ely B, Viñas J, Bremer JRA, et al (2005) Consequences of the historical demography on the global population structure of two highly migratory cosmopolitan marine fishes: the yellowfin tuna (Thunnus albacares) and the skipjack tuna (Katsuwonus pelamis). BMC Evol Biol 5:19

Erauskin Extramiana M, Arrizabalaga H, Hobday AJ, et al (2019) Large-scale distribution of tuna species in a warming ocean. Glob Change Biol 0: doi: 10.1111/gcb.14630

Eveson JP, Million J, Sardenne F, Le Croizier G (2015) Estimating growth of tropical tunas in the Indian Ocean using tag-recapture data and otolith-based age estimates. Fish Res 163:58-68. doi: 10.1016/j.fishres.2014.05.016

Fiorellato F, Geehan J, Pierre L (2018) Report on IOTC data collection and statistics. In: IOTC Proceedings. IOTC, Victoria, Seychelles, 29 November - 1 December 2018, 71p

Fonteneau A, Hallier J-P (2015) Fifty years of dart tag recoveries for tropical tuna: A global comparison of results for the western Pacific, eastern Pacific, Atlantic, and Indian Oceans. Fish Res 163:7-22. doi: 10.1016/j.fishres.2014.03.022

Fonteneau A, Lucas V, Tewkai E, et al (2008) Meso-scale exploitation of a major tuna concentration in the Indian Ocean. Aquat Living Resour 21:109-121

Fourmanoir P (1954) Ichthyologie et pêche aux Comores. Mém Inst Sci MadagascarSérie Biol Anim 9:187-239 
Fréon P, Dagorn L (2000) Review of fish associative behaviour: Toward a generalisation of the meeting point hypothesis. Rev Fish Biol Fish 10:183-207. doi: 10.1023/A:1016666108540

Fu D, Fiorellato F (2017a) Indian Ocean skipjack tuna stock assessment 1950-2016 (Stock Synthesis). In: IOTC Proceedings. Victoria, Seychelles, 17-22 October 2017, 85p

Gagern A, van den Bergh J (2013) A critical review of fishing agreements with tropical developing countries. Mar Policy 38:375-386. doi: 10.1016/j.marpol.2012.06.016

Galland G, Rogers A, Nickson A (2016) Netting billions: A global valuation of tuna. The PEW Charitable Trusts, Washington D.C., U.S.A.

Ganachaud A, Wunsch C, Marotzke J, Toole J (2000) Meridional overturning and large-scale circulation of the Indian Ocean. J Geophys Res Oceans 105:26117-26134. doi: 10.1029/2000JC900122

Geehan J, Fiorellato F (2017) Estimation of EEZ catches in the IOTC database: Report on the availability and quality of catch estimates. In: IOTC Proceedings. IOTC, Victoria, Seychelles, 30 Novermber - 4 December 2017, 14p

Geehan J, Fiorellato F, Pierre L (2016) Review of the statistical data and fishery trends for tropical tunas. In: IOTC Proceedings. Victoria, Seychelles, 5 -10 November 2016, 47p

Govinden R, Dagorn L, Soria M, Filmalter JD (2010) Behaviour of tuna associated with drifting fish aggregating devices (FADs) in the Mozambique Channel. In: IOTC Proceedings. IOTC, Victoria, Seychelles, 18-26 October 2010, 22p

Graham JB, Dickson KA (2004) Tuna comparative physiology. J Exp Biol 207:4015-4024. doi: 10.1242/jeb.01267

Grande M (2013) The reproductive biology, condition and feeding ecology of the skipjack, Katsuwonus pelamis, in the Western Indian Ocean. Universidad del Pais Vascos

Grande M, Murua H, Zudaire I, et al (2016) Energy allocation strategy of skipjack tuna Katsuwonus pelamis during their reproductive cycle. J Fish Biol 89:2434-2448. doi: 10.1111/jfb.13125

Grande M, Murua H, Zudaire I, et al (2014) Reproductive timing and reproductive capacity of the skipjack tuna (Katsuwonus pelamis) in the western Indian Ocean. Fish Res 156:14-22. doi: 10.1016/j.fishres.2014.04.011

Grewe PM, Feutry P, Hill PL, et al (2015) Evidence of discrete yellowfin tuna (Thunnus albacares) populations demands rethink of management for this globally important resource. Sci Rep 5:16916. doi: 10.1038/srep16916

Hall M (1992) The association of tunas with floating objects and dolphins. In: The association of tunas with floating objects and dolphins. La Jolla, California, 6p

Hallier JP, Fonteneau A (2015) Tuna aggregation and movement from tagging data: A tuna "hub" in the Indian Ocean. Fish Res 163:34-43. doi: 10.1016/j.fishres.2014.06.003

Hallier JP, Gaertner D (2008) Drifting fish aggregation devices could act as an ecological trap for tropical tuna species. Mar Ecol Prog Ser 353:255-264. doi: 10.3354/meps07180 
Hampton J (2000) Natural mortality rates in tropical tunas: size really does matter. Can J Fish Aquat Sci 57:1002-1010. doi: 10.1139/f99-287

Hassani S, Stéquert B (1991) Sexual maturity, spawning and fecundity of the yellowfin tuna (Thunnus albacares) of the Western Indian Ocean. IPTP Coll Vol Work 4:91-107

Hoenig JM, Barrowman NJ, Pollock KH, et al (1998) Models for tagging data that allow for incomplete mixing of newly tagged animals. Can J Fish Aquat Sci 55:1477-1483. doi: 10.1139/f97-258

Holland KN, Brill RW, Chang RKC, et al (1992) Physiological and behavioural thermoregulation in bigeye tuna (Thunnus obesus). Nature 358:410-412. doi: 10.1038/358410a0

Huggett JA (2014) Mesoscale distribution and community composition of zooplankton in the Mozambique Channel. Deep Sea Res Part II Top Stud Oceanogr 100:119-135. doi: 10.1016/ j.dsr2.2013.10.021

Hunter JR, Macewicz BJ (1985) Measurement of spawning frequency in multiple spawning fishes. NOAA Tech Rep NMFS 36:79-94

Hunter JR, Macewicz BJ, Sibert JR (1986) The spawning frequency of skipjack tuna, Katsuwonus pelamis, from the South Pacific. Fish Bull 84:895-903

IOTC (2018) Report of the 15th session of the compliance committee. IOTC, Bangkok, Thailand 13-15 and 17 May 2018

IOTC (2019) Report of the 5th Technical Committee on Allocation Criteria. IOTC, Victoria, Seychelles, 11-13 March 2019

ISSF (2014) Report of the ISSF Workshops on FADs as Ecological Traps, 29-31 January 2014 Sète, France. International Seafood Sustainability Foundation, Washington D.C., U.S.A.

Itano DG (2000) The reproductive biology of yellowfin tuna (Thunnus albacares) in Hawaiian waters and the western tropical Pacific Ocean: project summary. University of Hawaii, Joint Institute for Marine and Atmospheric Research

Jaquemet S, Potier M, Ménard F (2011) Do drifting and anchored Fish Aggregating Devices (FADs) similarly influence tuna feeding habits? A case study from the western Indian Ocean. Fish Res 107:283-290. doi: 10.1016/j.fishres.2010.11.011

Jones S, Kumaran M (1963) Distribution of larval tuna collected by the Carlsberg foundation's Dana expedition (1928-30) from the Indian Ocean. FAO Exp Pap 42 3:1753-1774

Juan-Jordá MJ, Mosqueira I, Freire J, Dulvy NK (2013) Life in 3-D: life history strategies in tunas, mackerels and bonitos. Rev Fish Biol Fish 23:135-155. doi: 10.1007/s11160-012-9284-4

Kambona JJ, Marashi SH (1996) Process for the establishment of the Indian Ocean Tuna Commission, FAO. FAO, Rome, Italy

Kaplan DM, Chassot E, Amandé JM, et al (2014a) Spatial management of Indian Ocean tropical tuna fisheries: potential and perspectives. ICES J Mar Sci 71:1728-1749. doi: 10.1093/icesjms/fst233 
Kojadinovic J, Potier M, Le Corre M, et al (2007) Bioaccumulation of trace elements in pelagic fish from the Western Indian Ocean. Environ Pollut 146:548-566. doi: 10.1016/j.envpol.2006.07.015

Kolody D, Grewe P, Davies C, Proctor C (2013) Are Indian Ocean tuna populations assessed and managed at the appropriate spatial scale? A brief review of the evidence and implications. In: IOTC Proceedings. IOTC, San Sebastian, Spain, 23-28 October 2013, 18p

Kolody D, Hoyle S (2013) Evaluation of tag mixing assumptions for skipjack, yellowfin and bigeye tuna stock assessments in the Western Pacific and Indian Oceans. WCPFC, Pohnpei, Federated States of Micronesia, 6-14 August 2013, 26p

Kolody D, Eveson JP, Hillary RM (2016) Modelling growth in tuna RFMO stock assessments: Current approaches and challenges. Fish Res 180:177-193. doi: 10.1016/j.fishres.2015.06.016

Kroodsma DA, Mayorga J, Hochberg T, et al (2018) Tracking the global footprint of fisheries. Science 359:904-908. doi: 10.1126/science.aao5646

Kunal SP, Kumar G, Menezes MR, Meena RM (2013) Mitochondrial DNA analysis reveals three stocks of yellowfin tuna Thunnus albacares (Bonnaterre, 1788) in Indian waters. Conserv Genet 14:205-213

Langley A (2015) Stock assessment of yellowfin tuna in the Indian Ocean using Stock Synthesis. In: IOTC Proceedings. IOTC, 23-28 October 2015, Montpellier, France, 82p

Langley A (2016a) Stock assessment of bigeye tuna in the Indian Ocean for 2016 - model development and evaluation. In: IOTC Proceedings. IOTC, Victoria, Seychelles, 11-13 November 2016, 98p

Langley A (2016b) An update of the 2015 Indian Ocean yellowfin tuna stock assessment for 2016. In: IOTC Proceedings. IOTC, Victoria, Seychelles, 11-13 November 2016, 14p

Langley A (2013) BET IO tag dispersal -- a simple model. presentation.

Langley A, Million J (2012) Determining an appropriate tag mixing period for the Indian Ocean yellowfin tuna stock assessment. IOTC, Grand Baie, Mauritius, 24-29 October 2012, 53p

Laran S, Authier M, Van Canneyt O, et al (2017) A comprehensive survey of pelagic megafauna: their distribution, densities, and taxonomic richness in the tropical southwest Indian Ocean. Front Mar Sci 4:. doi: 10.3389/fmars.2017.00139

Le Manach F, Gough C, Harris A, et al (2012) Unreported fishing, hungry people and political turmoil: the recipe for a food security crisis in Madagascar? Mar Policy 36:218-225. doi: 10.1016/j.marpol.2011.05.007

Lebourges-Dhaussy A, Huggett J, Ockhuis S, et al (2014) Zooplankton size and distribution within mesoscale structures in the Mozambique Channel: A comparative approach using the TAPS acoustic profiler, a multiple net sampler and ZooScan image analysis. Deep Sea Res Part II Top Stud Oceanogr 100:136-152. doi: 10.1016/j.dsr2.2013.10.022 
Llopiz JK, Richardson DE, Shiroza A, et al (2010) Distinctions in the diets and distributions of larval tunas and the important role of appendicularians. Limnol Oceanogr 55:983-996. doi: 10.4319/lo.2010.55.3.0983

Lopez J, Moreno G, Ibaibarriaga L, Dagorn L (2017) Diel behaviour of tuna and non-tuna species at drifting fish aggregating devices (DFADs) in the Western Indian Ocean, determined by fishers’ echo-sounder buoys. Mar Biol 164:. doi: 10.1007/s00227-017-3075-3

Lorrain A, Graham BS, Popp BN, et al (2015) Nitrogen isotopic baselines and implications for estimating foraging habitat and trophic position of yellowfin tuna in the Indian and Pacific Oceans. Deep Sea Res Part II Top Stud Oceanogr 113:188-198. doi: 10.1016/j.dsr2.2014.02.003

Magnuson JJ (1973) Comparative study of adaptations for continuous swimming and hydrostatic equilibrium of scombroid and xiphoid fishes. Fish Bull 71:337-356

Magnuson JJ (1978) 4 - Locomotion by scombrid fishes: Hydromechanics, morphology, and behavior. In: Hoar WS, Randall DJ (eds) Fish Physiology. Academic Press, pp 239-313

Malone MA, Buck KM, Moreno G, Sancho G (2011) Diet of three large pelagic fishes associated with drifting fish aggregating devices (DFADs) in the western equatorial Indian Ocean. Anim Biodivers Conserv 34:287-294

Marcille J, Veillon P (1973) Prospections et pêches thonières au Nord et à l'Ouest de Madagascar en 1972. ORSTOM, Nosy-Bé

Margulies D, Sutter JM, Hunt SL, et al (2007) Spawning and early development of captive yellowfin tuna (Thunnus albacares). Fish Bull 105:249-265

Marsac F, Fonteneau A, Ménard F (2000) Drifting FADs used in tuna fisheries: an ecological trap? Le Gall, J.-Y., Cayré, P., Taquet M., pp 537-552

Martin S, Fiorellato F, Geehan J (2016) A pilot project for the IOTC Regional Observer Scheme. In: IOTC Proceedings. IOTC, Victoria, Seychelles, 28-30 November 2016, 23p

Matsumoto T, Satoh K, Toyonaga M (2014) Behavior of skipjack tuna (Katsuwonus pelamis) associated with a drifting FAD monitored with ultrasonic transmitters in the equatorial central Pacific Ocean. Fish Res 157:78-85. doi: 10.1016/j.fishres.2014.03.023

Maufroy A, Kaplan DM, Bez N, et al (2017) Massive increase in the use of drifting Fish Aggregating Devices (dFADs) by tropical tuna purse seine fisheries in the Atlantic and Indian oceans. ICES J Mar Sci 74:215-225. doi: 10.1093/icesjms/fsw175

Maury O (2017) Can schooling regulate marine populations and ecosystems? Prog Oceanogr 156:91-103. doi: 10.1016/j.pocean.2017.06.003

McBride RS, Somarakis S, Fitzhugh GR, et al (2015) Energy acquisition and allocation to egg production in relation to fish reproductive strategies. Fish Fish 16:23-57. doi: 10.1111/faf.12043 
McPherson GR (1991) Reproductive biology of yellowfin tuna in the eastern Australian Fishing Zone, with special reference to the north-western Coral Sea. Mar Freshw Res 42:465-477. doi: 10.1071/mf9910465

Ménard F, Benivary HD, Bodin N, et al (2014) Stable isotope patterns in micronekton from the Mozambique Channel. Deep Sea Res Part II Top Stud Oceanogr 100:153-163. doi: 10.1016/ j.dsr2.2013.10.023

Ménard F, Lorrain A, Potier M, Marsac F (2007) Isotopic evidence of distinct feeding ecologies and movement patterns in two migratory predators (yellowfin tuna and swordfish) of the western Indian Ocean. Mar Biol 153:141-152. doi: 10.1007/s00227-007-0789-7

Menezes MR, Kumar G, Kunal SP (2012) Population genetic structure of skipjack tuna Katsuwonus pelamis from the Indian coast using sequence analysis of the mitochondrial DNA D-loop region. J Fish Biol 80:2198-2212. doi: 10.1111/j.1095-8649.2012.03270.x

Miyake MP, Guillotreau P, ChinHwa S, et al (2010) Recent developments in the tuna industry: stocks, fisheries, management, processing, trade and markets. FAO Fish Aquac Tech Pap 543:97

Moreno G (2013) Pilot project to improve data collection for tuna, sharks and billfish from artisanal fisheries in the Indian Ocean. FAO, Victoria, Seychelles

Murua H, Eveson JP, Marsac F (2015) The Indian Ocean Tuna Tagging Programme: Building better science for more sustainability. Fish Res 163:1-6. doi: 10.1016/j.fishres.2014.07.001

Murua H, Rodriguez-Marin E, Neilson JD, et al (2017) Fast versus slow growing tuna species: age, growth, and implications for population dynamics and fisheries management. Rev Fish Biol Fish 1-41. doi: 10.1007/s11160-017-9474-1

Mutombene R, Sulemane NB, Salença A, et al (2017) General characterization of artisanal purse seine and handline fisheries of northern coast of Mozambique and their impact on tuna and tuna like species. In: IOTC Proceedings. IOTC, Victoria Mahé, 26-28 November 2017, 31p

Obura DO, Burgener V, Nicoll ME, et al (2015) The Northern Mozambique Channel. Setting the foundations for a regional approach to marine governance. WWF International and CORDIO East Africa, Mombasa, Kenya

Obura DO, Bandeira SO, Bodin N, et al (2018) The Northern Mozambique Channel. In: World seas: An environmental evaluation: 2- The Indian Ocean to the Pacific. C. Sheppard

Palastanga V, van Leeuwen PJ, de Ruijter WPM (2006) A link between low-frequency mesoscale eddy variability around Madagascar and the large-scale Indian Ocean variability. J Geophys Res Oceans 111:C09029. doi: 10.1029/2005JC003081

Pecoraro C, Babbucci M, Franch R, et al (2018) The population genomics of yellowfin tuna (Thunnus albacares ) at global geographic scale challenges current stock delineation. Sci Rep 8:13890. doi: 10.1038/s41598-018-32331-3

Pecoraro C, Zudaire I, Bodin N, et al (2016) Putting all the pieces together: integrating current knowledge of the biology, ecology, fisheries status, stock structure and management of 
yellowfin tuna (Thunnus albacares). Rev Fish Biol Fish 1-31. doi: 10.1007/s11160-0169460-z

Pepperell J, Griffiths S, Kadagi N (2017) Acquisition of catch-and-effort and size data from sport fisheries in the Western Indian Ocean. In: IOTC Proceedings. IOTC, Victoria, Seychelles, 26-28 November 2017, 100p

Pethybridge H, Choy CA, Logan JM, et al (2018) A global meta-analysis of marine predator nitrogen stable isotopes: Relationships between trophic structure and environmental conditions. Glob Ecol Biogeogr 27:1043-1055. doi: 10.1111/geb.12763

Petit G (1923) La vie sur les côtes de Madagascar et l'industrie indigène de la pêche. Ann Géographie 32:142-164. doi: 10.3406/geo.1923.9975

Popova E, Yool A, Byfield V, et al (2016) From global to regional and back again: common climate stressors of marine ecosystems relevant for adaptation across five ocean warming hotspots. Glob Change Biol 22:2038-2053. doi: 10.1111/gcb.13247

Potier M, Bach P, Ménard F, Marsac F (2014) Influence of mesoscale features on micronekton and large pelagic fish communities in the Mozambique Channel. Deep Sea Res Part II Top Stud Oceanogr 100:184-199. doi: 10.1016/j.dsr2.2013.10.026

Potier M, Marsac F, Cherel Y, et al (2007) Forage fauna in the diet of three large pelagic fish (lancetfish, swordfish and yellowfin tuna) in the western equatorial Indian Ocean. Fish Res 83:60-72. doi: 10.1016/j.fishres.2006.08.020

Potier M, Marsac F, Lucas V, et al (2004) Feeding partitioning among tuna taken in surface and mid-water layers: The case of Yellowfin (Thunnus albacares) and bigeye ( $T$. obesus) in the western tropical Indian Ocean. West Indian Ocean J Mar Sci 3:51-62

Potier M, Marsac F, Lucas V, et al (2002) On-going research activities on trophic ecology of tuna in equatorial ecosystems of the Indian Ocean. In: IOTC Proceedings. IOTC, Shanghai, China, 03-11 June 2002, pp 368-374

Potier M, Ménard F, Benivary HD, Sabatié R (2011) Length and weight estimates from diagnostic hard part structures of fish, crustacea and cephalopods forage species in the western Indian Ocean. Environ Biol Fishes 92:413-423. doi: 10.1007/s10641-011-9848-5

Potier M, Romanov E, Cherel Y, et al (2008a) Spatial distribution of Cubiceps pauciradiatus (Perciformes:Nomeidae) in the tropical Indian Ocean and its importance in the diet of large pelagic fishes. Aquat Living Resour 21:123-134. doi: 10.1051/alr:2008026

Potier M, Romanov E, Cherel Y, et al (2008b) Spatial distribution of Cubiceps pauciradiatus (Perciformes:Nomeidae) in the tropical Indian Ocean and its importance in the diet of large pelagic fishes. Aquat Living Resour 21:123-134. doi: 10.1051/alr:2008026

Ranaivoson E, Ranaivoarison A (2013) Auto-évaluation des pêches comoriennes par les pêcheurs. COI, Ebène, Mauritius

Reglero P, Tittensor DP, Álvarez-Berastegui D, et al (2014) Worldwide distributions of tuna larvae: revisiting hypotheses on environmental requirements for spawning habitats. Mar Ecol Prog Ser 501:207-224. doi: 10.3354/meps10666 
Richards WJ, Simmons DC (1971) Distribution of tuna larvae (Pisces, Scombridae) in the northwestern Gulf of Guinea and off Sierra Leone. Fish Bull 69:555-68

Richmond MD, Mohamed A (2006) The Tanzania FAD programme

Rieucau G, Fernö A, Ioannou CC, Handegard NO (2015) Towards of a firmer explanation of large shoal formation, maintenance and collective reactions in marine fish. Rev Fish Biol Fish 25:21-37. doi: 10.1007/s11160-014-9367-5

Roberts MJ, Ternon J-F, Morris T (2014) Interaction of dipole eddies with the western continental slope of the Mozambique Channel. Deep Sea Res Part II Top Stud Oceanogr 100:54-67. doi: 10.1016/j.dsr2.2013.10.016

Roger C (1994) Relationships among yellowfin and skipjack tuna, their prey-fish and plankton in the tropical western Indian Ocean. Fish Oceanogr 3:133-141. doi: 10.1111/j.13652419.1994.tb00055.x

Romanov E, Potier M, Zamorov V, Ménard F (2009) The swimming crab Charybdis smithii: distribution, biology and trophic role in the pelagic ecosystem of the western Indian Ocean. Mar Biol 156:1089-1107. doi: 10.1007/s00227-009-1151-z

Roxy MK, Modi A, Murtugudde R, et al (2016) A reduction in marine primary productivity driven by rapid warming over the tropical Indian Ocean. Geophys Res Lett 43:826-833. doi: 10.1002/2015GL066979

Roxy MK, Ritika K, Terray P, Masson S (2014) The curious case of Indian Ocean warming. J Clim 27:8501-8509. doi: 10.1175/jcli-d-14-00471.1

Sabarros PS, Ménard F, Lévénez J-J, et al (2009) Mesoscale eddies influence distribution and aggregation patterns of micronekton in the Mozambique Channel. Mar Ecol Prog Ser 395:101-107. doi: 10.3354/meps08087

Sabarros PS, Romanov EV, Bach P (2017) Movements and behaviour of yellowfin and bigeye tuna associated to oceanic structures in the western Indian Ocean. In: IOTC Proceedings. IOTC, Victoria, Seychelles, 17-22 October 2017, 14p

Sardenne F, Bodin N, Chassot E, et al (2016) Trophic niches of sympatric tropical tuna in the Western Indian Ocean inferred by stable isotopes and neutral fatty acids. Prog Oceanogr 146:75-88. doi: 10.1016/j.pocean.2016.06.001

Sardenne F, Dortel E, Le Croizier G, et al (2015) Determining the age of tropical tunas in the Indian Ocean from otolith microstructures. Fish Res 163:44-57. doi: 10.1016/j.fishres.2014.03.008

Schaefer K, Fuller D, Hampton J, et al (2015) Movements, dispersion, and mixing of bigeye tuna (Thunnus obesus) tagged and released in the equatorial Central Pacific Ocean, with conventional and archival tags. Fish Res 161:336-355. doi: 10.1016/j.fishres.2014.08.018

Schaefer KM (1996) Spawning time, frequency, and batch fecundity of yellowfin tuna, Thunnus albacares near Clipperton Atoll in the eastern Pacific Ocean. Fish Bull 94:98-112

Schaefer KM (2001) Reproductive biology of tunas. In: Tuna: Physiology, Ecology, and Evolution. Academic Press, pp 225-270 
Schaefer KM, Fuller D, Miyabe N (2005) Reproductive biology of bigeye tuna (Thunnus obesus) in the eastern and central Pacific Ocean. IATTC Bull 23:33

Schaefer KM, Fuller DW (2013) Simultaneous behavior of skipjack (Katsuwonus pelamis), bigeye (Thunnus obesus), and yellowfin (T. albacares) tunas, within large multi-species aggregations associated with drifting fish aggregating devices (FADs) in the equatorial eastern Pacific Ocean. Mar Biol 1-10. doi: 10.1007/s00227-013-2290-9

Schott FA, Xie S-P, Jr JPM (2009) Indian Ocean circulation and climate variability. Rev Geophys 47:46 PP. doi: 200910.1029/2007RG000245

Schouten MW, de Ruijter WPM, Ridderinkhof H (2005) A seasonal intrusion of subtropical water in the Mozambique Channel. Geophys Res Lett 32:L18601. doi: 10.1029/2005GL023131

Schouten MW, de Ruijter WPM, van Leeuwen PJ, Ridderinkhof H (2003) Eddies and variability in the Mozambique Channel. Deep Sea Res Part II Top Stud Oceanogr 50:1987-2003. doi: 10.1016/S0967-0645(03)00042-0

Sequeira A, Mellin C, Rowat D, et al (2012) Ocean-scale prediction of whale shark distribution. Divers Distrib 18:504-518. doi: 10.1111/j.1472-4642.2011.00853.x

Soilihi AS (2017) Union des Comores Rapport national destiné au Comité scientifique de la Commission des thons de l'océan Indien, 2017. In: IOTC Proceedings. IOTC, Victoria, Seychelles, 30 November - 04 December 2017, 8p

Stéquert B (1976) Etude de la maturité sexuelle, de la ponte et de la fécondité du listao (Katsuwonus pelamis) de la côte nord-ouest de Madagascar. Cah ORSTOM Sér Océan $14: 227-247$

Stéquert B, Marsac F (1989) Tropical tuna - Surface fisheries in the Indian Ocean. Rome, Italy

Stéquert B, Ramcharrun B (1996) La reproduction du listao (Katsuwonus pelamis) dans le bassin ouest de l’océan Indien. Aquat Living Resour 9:235-247. doi: 10.1051/alr:1996027

Stéquert B, Ramcharrun B (1995) La fécondité du listao (Katsuwonus pelamis) de l'ouest de l’océan Indien. Aquat Living Resour 8:79-89. doi: 10.1051/alr:1995006

Stéquert B, Rodriguez JN, Cuisset B, Menn FL (2001) Gonadosomatic index and seasonal variations of plasma sex steroids in skipjack tuna (Katsuwonus pelamis) and yellowfin tuna (Thunnus albacares) from the western Indian ocean. Aquat Living Resour 14:313-318. doi: 10.1016/S0990-7440(01)01126-3

Suman A, Irianto HE, Amri K, Nugraha B (2013) Population structure and reproduction of big eye tuna (Thunnus obesus) in Indian Ocean at western part of Sumatra and southern part of Java and Nusa Tengarra. In: IOTC Proceedings. IOTC, San Sebastian, Spain, 23-28 October 2013, 14p

Sun CL, Yeh SZ, Chang YJ, et al (2013) Reproductive biology of female bigeye tuna Thunnus obesus in the western Pacific Ocean. J Fish Biol 83:250-271. doi: 10.1111/jfb.12161

Tahindro A (2004) The implementation of UNCLOS in the Indian Ocean region: the case of Madagascar. Afr Yearb Int Law 12:349-435 
Teh LSL, Teh LCL, Sumaila UR (2011) Quantifying the overlooked socio-economic contribution of small-scale fisheries in Sabah, Malaysia. Fish Res 110:450-458. doi: 10.1016/j.fishres.2011.06.001

Tew Kai E, Marsac F (2010) Influence of mesoscale eddies on spatial structuring of top predators' communities in the Mozambique Channel. Prog Oceanogr 86:214-223. doi: 10.1016/j.pocean.2010.04.010

Tew-Kai E, Marsac F (2009) Patterns of variability of sea surface chlorophyll in the Mozambique Channel:A quantitative approach. J Mar Syst 77:77-88. doi: 10.1016/j.jmarsys.2008.11.007

Toihir IM (2017) Six years for improving statistic data collection in Comoros. In: IOTC Proceedings. IOTC, Victoria, Seychelles, 26-28 November 2017, 14p

van der Elst R, Everett B, Jiddawi N, et al (2005) Fish, fishers and fisheries of the Western Indian Ocean: their diversity and status. A preliminary assessment. Philos Trans R Soc Math Phys Eng Sci 363:263-284

Venkatasami A (1990) Introduction of Fish Aggregating Devices in the Southwest Indian Ocean (a case study). FAO, Colombo, Sri Lanka, May 1990, 27p

Wang X, Chen Y, Truesdell S, et al (2014) The large-scale deployment of fish aggregation devices alters environmentally-based migratory behavior of skipjack tuna in the Western Pacific Ocean. PLoS ONE 9:e98226. doi: 10.1371/journal.pone.0098226

Ward P, Hindmarsh S (2007) An overview of historical changes in the fishing gear and practices of pelagic longliners, with particular reference to Japan’s Pacific fleet. Rev Fish Biol Fish 17:501-516. doi: 10.1007/s11160-007-9051-0

Weimerskirch H, Corre ML, Jaquemet S, et al (2004) Foraging strategy of a top predator in tropical waters: great frigatebirds in the Mozambique Channel. Mar Ecol Prog Ser 275:297-308

Whitlock RE, Hazen EL, Walli A, et al (2015) Direct quantification of energy intake in an apex marine predator suggests physiology is a key driver of migrations. Sci Adv 1:e1400270. doi: 10.1126/sciadv.1400270

Williams AJ, Leroy BM, Nicol SJ, et al (2013) Comparison of daily- and annual- increment counts in otoliths of bigeye (Thunnus obesus), yellowfin ( $T$. albacares), southern bluefin ( $T$. maccoyii) and albacore (T. alalunga) tuna. ICES J Mar Sci J Cons 70:1439-1450. doi: 10.1093/icesjms/fst093

Young JW, Davis TLO (1990) Feeding ecology of larvae of southern bluefin, albacore and skipjack tunas (Pisces: Scombridae) in the eastern Indian Ocean. Mar Ecol Prog Ser 61:17-29

Yuen HSH (1966) Swimming speeds of yellowfin and skipjack tuna. Trans Am Fish Soc 95:203209. doi: 10.1577/1548-8659(1966)95[203:SSOYAS]2.0.CO;2

Zudaire I, Chassot E, Murua H, et al (2016) Sex-ratio, size at maturity, spawning period and fecundity of bigeye tuna (Thunnus obesus) in the western Indian Ocean. In: IOTC Proceedings. IOTC, Victoria, Seychelles, 5-10 November 2016, 19p 
Zudaire I, Murua H, Grande M, et al (2015) Variations in the diet and stable isotope ratios during the ovarian development of female yellowfin tuna (Thunnus albacares) in the Western Indian Ocean. Mar Biol 162:2363-2377

Zudaire I, Murua H, Grande M, et al (2014) Accumulation and mobilization of lipids in relation to reproduction of yellowfin tuna (Thunnus albacares) in the Western Indian Ocean. Fish Res 160:50-59. doi: 10.1016/j.fishres.2013.12.010

Zudaire I, Murua H, Grande M, Bodin N (2013) Reproductive potential of the yellowfin tuna (Thunnus albacares) in the western Indian Ocean. Fish Bull 111:252-264 


\section{List of tables}

867 Table 1. Contribution of the Exclusive Economic Zone (EEZ) of each country to the Northern

868 Mozambique Channel (NMC). Total surface area and area within the NMC are given in $\mathrm{km}^{2}$.

869

870 Table 2. Summary of the main biological features of Indian Ocean tropical tunas. Observations of

871 maximum size available from IOTC. Growth: Eveson et al. (2015). Maturity and fecundity: Grande 872 et al. (2014), Zudaire et al. (2013, 2016). Natural mortality: Fu and Fiorellato (2017), Langley et al.

873 (2015, 2016). † Constant value used in the grid of skipjack assessments (Fu and Fiorellato 2017)

874

875 Table 3. Summary table of the main characteristics of the past and current protocols under the

876 Fisheries Partnership Agreement between the European Union and Comoros, Madagascar, and 877 Mozambique. Financial contributions were calculated as an average of the annual payments 878 


\section{List of figures}

880 Fig. 1. Location of the Northern Mozambique Channel in the Western Indian Ocean (dashed line).

881 Coloured solid lines indicate the Exclusive Economic Zones of Tanzania (TZA), Mozambique

882 (MOZ), Comoros (COM), Mayotte (MYT), and Madagascar (MDG). Grey scale represents the

883 bathymetry (m)

884

885 Fig. 2. Vorticity of the meridional velocity of a typical anticyclonic eddy (indicated by black arrow) 886 identified from satellite altimetry data and a high-resolution ocean circulation model at the time of 887 formation (a; 20 August), location within the central Comoros basin (b; 23 September), and upon 888 leaving the basin (c; 29 November) (Collins et al. 2014).

890 Fig. 3. Annual time series of catch (mt) by species group for the tuna and tuna-like species caught 891 by the coastal fisheries of the countries bordering the Northern Mozambique Channel 892

893 Fig. 4. Annual time series of tropical tuna catch of high seas (a) longliners and (b) purse seiners 894 within the Northern Mozambique Channel (NMC). Solid line indicates estimates based on 895 assumption of evenly distribution of the public-domain gridded catch intersected with NMC area. 896 Dotted lines represents the uncertainty on catch estimated through lower and higher bounds based on assumptions of exclusion and inclusion of all catches intersected by NMC boundaries, respectively

900 Fig. 5. Mean annual monthly catch (mt) of tropical tunas by high seas purse seiners (black solid line 901 with dots) and longliners (red dashed line with crosses) during 2007-2016 902 
903 Fig. 6. Linear trajectories between tagging and recovery positions of skipjack (SKJ; $n=135)$,

904 bigeye (BET; $\mathrm{n}=119$ ), and yellowfin (YFT; $\mathrm{n}=108$ ) tagged with dart tags within the Northern

905 Mozambique Channel (solid black line). Positions of tagging are indicated with grey open circles.

906 The number of mark-recaptures was sub-sampled for readability.

907

908 Fig. 7. Distribution of apparent distance travelled (nm) by month during the first 5 months at 909 liberty of tropical tunas tagged with dart tags within the Northern Mozambique Channel. SKJ = 910 skipjack; BET = bigeye; YFT = yellowfin.

911

Fig. 8. Mean growth curves in fork length (cm) for bigeye (BET), yellowfin (YFT), and skipjack (SKJ) tuna derived from integrated statistical models (Eveson et al. 2015).

913 Fig. 9. Distribution of individual growth rates $\left(\mathrm{cm} \mathrm{mo}^{-1}\right)$ as a function of average length between 914 tagging and recapture for skipjack (SKJ) and juveniles of bigeye (BET) and yellowfin (YFT) tagged 915 with dart tags within the Northern Mozambique Channel.

917 Fig. 10. Relationship between batch fecundity and standardized fish length (fork length divided by 918 the mean) for Indian Ocean yellowfin (YFT; Zudaire et al. 2013), bigeye (BET; Zudaire et al. 2016), 919 and skipjack (SKJ; Grande et al. 2014). Dashed lines indicate non-linear 75\% quantile regression 920 models fitted to each data set.

922 Fig. 11. Relationships between gonad weight (g) and total weight (kg) for Indian Ocean skipjack 923 (SKJ), bigeye (BET), and yellowfin (YFT). Lines indicate 10\% (dashed), 50\% (solid) and 90\% 924 (dotted) non-linear quantile regression models fitted to the data. 
925 TABLES

926 Table 1. Contribution of the Exclusive Economic Zone (EEZ) of each country to the Northern Mozambique Channel (NMC). Total surface area and 927 area within the NMC are given in $\mathrm{km}^{2}$.

\begin{tabular}{lrrrr}
\hline EEZ & $\begin{array}{l}\text { Area } \\
\left(\mathrm{km}^{2}\right)\end{array}$ & $\begin{array}{c}\text { Area within } \\
\text { NMC } \\
\left(\mathrm{km}^{2}\right)\end{array}$ & $\begin{array}{c}\text { Part within } \\
\text { NMC } \\
(\%)\end{array}$ & $\begin{array}{c}\text { Contribution } \\
(\%)\end{array}$ \\
\hline Comoros & 164781 & 164781 & 100 & 21 \\
Madagascar & 1239905 & 253493 & 20 & 33 \\
Mayotte & 63011 & 63011 & 100 & 8 \\
Mozambique & 566114 & 180960 & 32 & 24 \\
Tanzania & 241445 & 106997 & 44 & 14 \\
\hline
\end{tabular}



al. (2015, 2016). † Constant value used in the grid of skipjack assessments (Fu and Fiorellato 2017)

\begin{tabular}{|c|c|c|c|c|c|c|c|c|}
\hline Function & Feature & Parameter & Definition & Notation & Unit & SKJ & YFT & BET \\
\hline \multirow[t]{4}{*}{ Growth } & Lifespan & Maximum length & Maximum fork length observed in the wild & $L_{\text {Fmax }}$ & $\mathrm{cm}$ & 100 & 200 & 206 \\
\hline & & Maximum weight & Maximum total weight observed in the wild & $W_{\text {Tmax }}$ & $\mathrm{kg}$ & 30 & 165 & 207 \\
\hline & & Longevity & Maximum age & $A_{\max }$ & $\mathrm{y}$ & 7 & 9 & 15 \\
\hline & Growth & Growth rate & Initial growth coefficient of the stanza growth & $K_{1}$ & $\mathrm{y}^{-1}$ & 1.41 & 0.21 & 0.06 \\
\hline \multirow[t]{5}{*}{ Reproduction } & Maturity & $\begin{array}{l}\text { Length at } \\
\text { maturity }\end{array}$ & $\begin{array}{l}\text { Fork length at which } 50 \% \text { of the females are mature, i.e. ovaries are } \\
\text { classified in developing phase following the presence of oocytes in } \\
\text { cortical alveolar stage as the most advanced developmental stage }\end{array}$ & $L_{\text {Fmat }}$ & $\mathrm{cm}$ & 40 & 75 & 102 \\
\hline & & $\begin{array}{l}\text { Weight at } \\
\text { maturity }\end{array}$ & Total weight at which $50 \%$ of the females are mature & $W_{\text {Tmat }}$ & $\mathrm{kg}$ & 1.3 & 8.9 & 25 \\
\hline & & Age at maturity & Age at which $50 \%$ of the females are mature & $A_{\text {mat }}$ & $\mathrm{y}$ & 0.6 & 2.3 & 3 \\
\hline & Fecundity & Batch fecundity & $\begin{array}{l}\text { Average number of oocytes (million) in the stages of hydration, } \\
\text { germinal vesicle migration and breakdown in the ovary }\end{array}$ & $F_{B}$ & eggs & $0.28 \pm 0.15$ & $3.22 \pm 1.78$ & $0.72 \pm 0.56$ \\
\hline & & $\begin{array}{l}\text { Relative batch } \\
\text { fecundity }\end{array}$ & Ratio between batch fecundity and gonad-free weight of the fish & $F_{R B}$ & eggs $g^{-1}$ & $136 \pm 66$ & $76 \pm 40$ & $10 \pm 7$ \\
\hline Mortality & Natural & Annual rate ${ }^{\dagger}$ & Natural mortality rate & $M$ & $\mathrm{y}^{-1}$ & $0.8^{+}$ & $0.54-1.34$ & 025-0.8 \\
\hline
\end{tabular}


937 Table 3. Summary table of the main characteristics of the past protocols under the Fisheries

938 Partnership Agreement between the European Union and Comoros, Madagascar, and Mozambique.

939 Financial contributions were calculated as an average of the annual payments.

\begin{tabular}{lrrr}
\hline Country & Comoros & Madagascar & Mozambique \\
\hline Start date & $2014-01-01$ & $2015-01-01$ & $2012-02-01$ \\
End date & $2016-12-30$ & $2018-12-31$ & $2015-01-31$ \\
Number of purse seiners & 42 & 43 & 44 \\
Number of longliners & 20 & 81 & 45 \\
Annual total contribution $(€)$ & 600000 & 1526875 & 980000 \\
Annual sectoral support $(€)$ & 300000 & 700000 & 460000 \\
Annual access right & 300000 & 826875 & 520000 \\
Reference tonnage $(\mathrm{mt})$ & 6000 & 15750 & 8000 \\
Shipowners contribution $(€ / \mathrm{mt})$ & 55 & 65 & 35 \\
\hline
\end{tabular}

940

941 


\section{FIGURES}

944

945

946

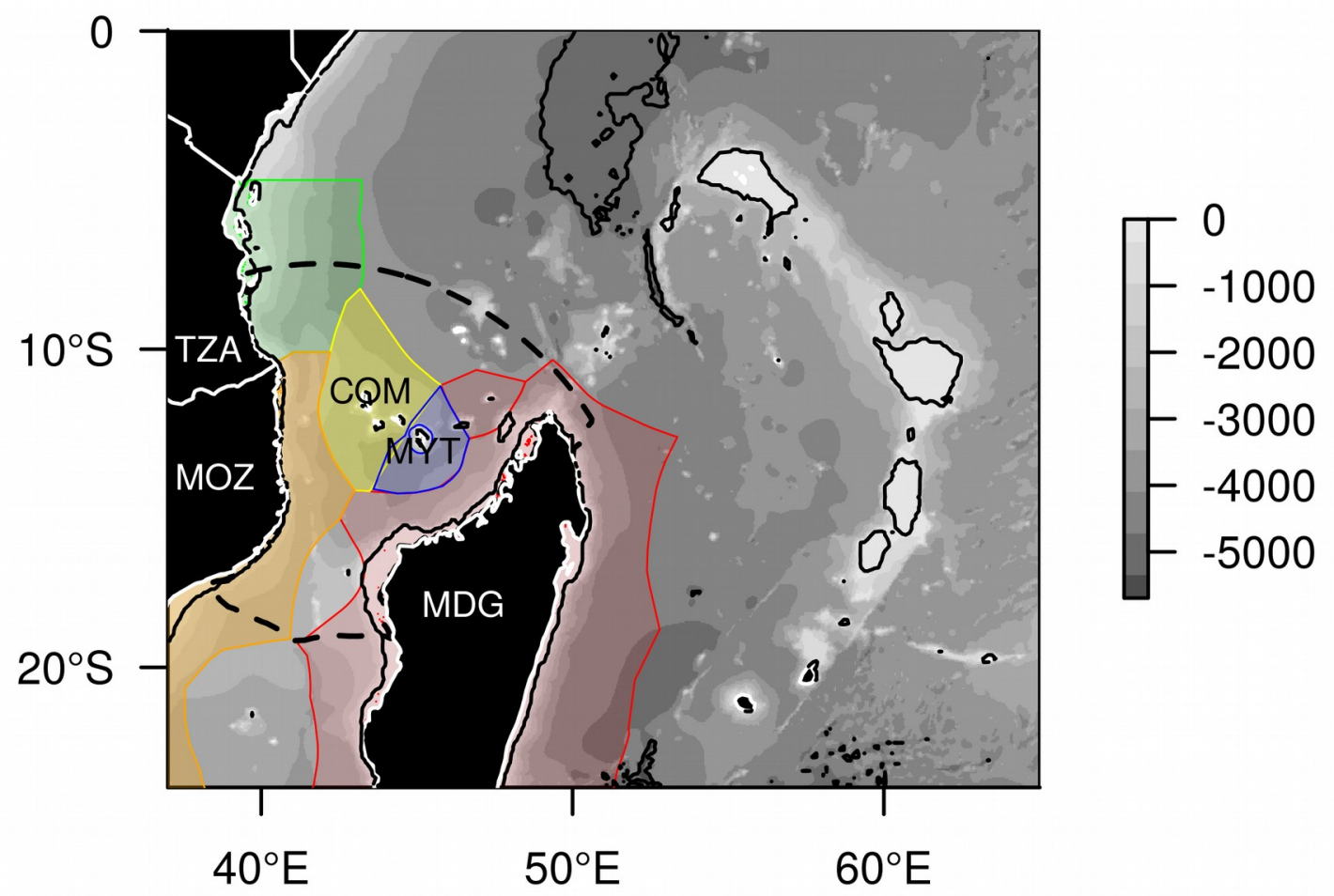

Fig. 1: Location of the Northern Mozambique Channel in the Western Indian Ocean (dashed line). Coloured solid lines indicate the Exclusive Economic Zones of Tanzania (TZA), Mozambique (MOZ), Comoros (COM), Mayotte (MYT), and Madagascar (MDG). Grey scale represents the bathymetry (m). 
a) Vorticity - 20 Aug of model year 7

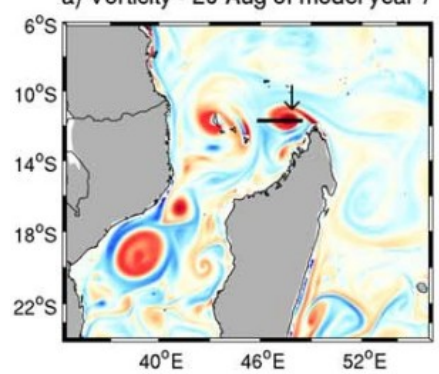

b) Vorticity - 23 Sep of model year 7

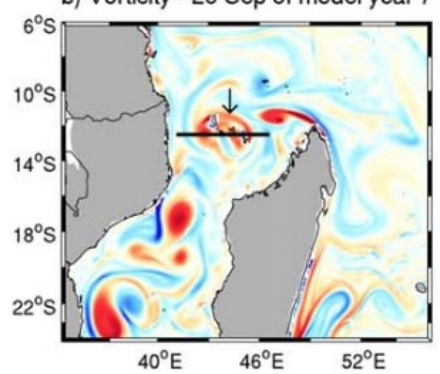

c) Vorticity - 29 Nov of model year 7

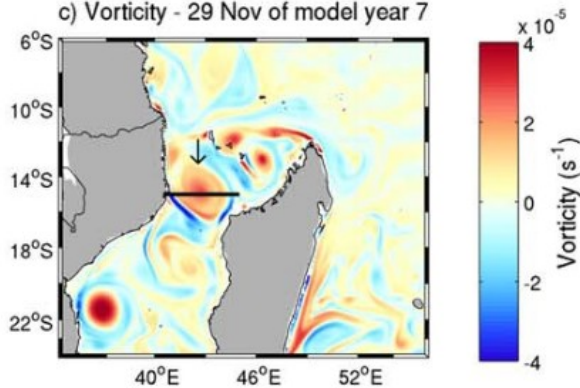

Fig. 2: Vorticity of the meridional velocity of a typical anticyclonic eddy (indicated by black arrow) identified from satellite altimetry data and a high-resolution ocean circulation model at the time of formation (a; 20 August), location within the central Comoros basin (b; 23 September), and upon leaving the basin (c; 29 November) (Collins et al. 2014). 


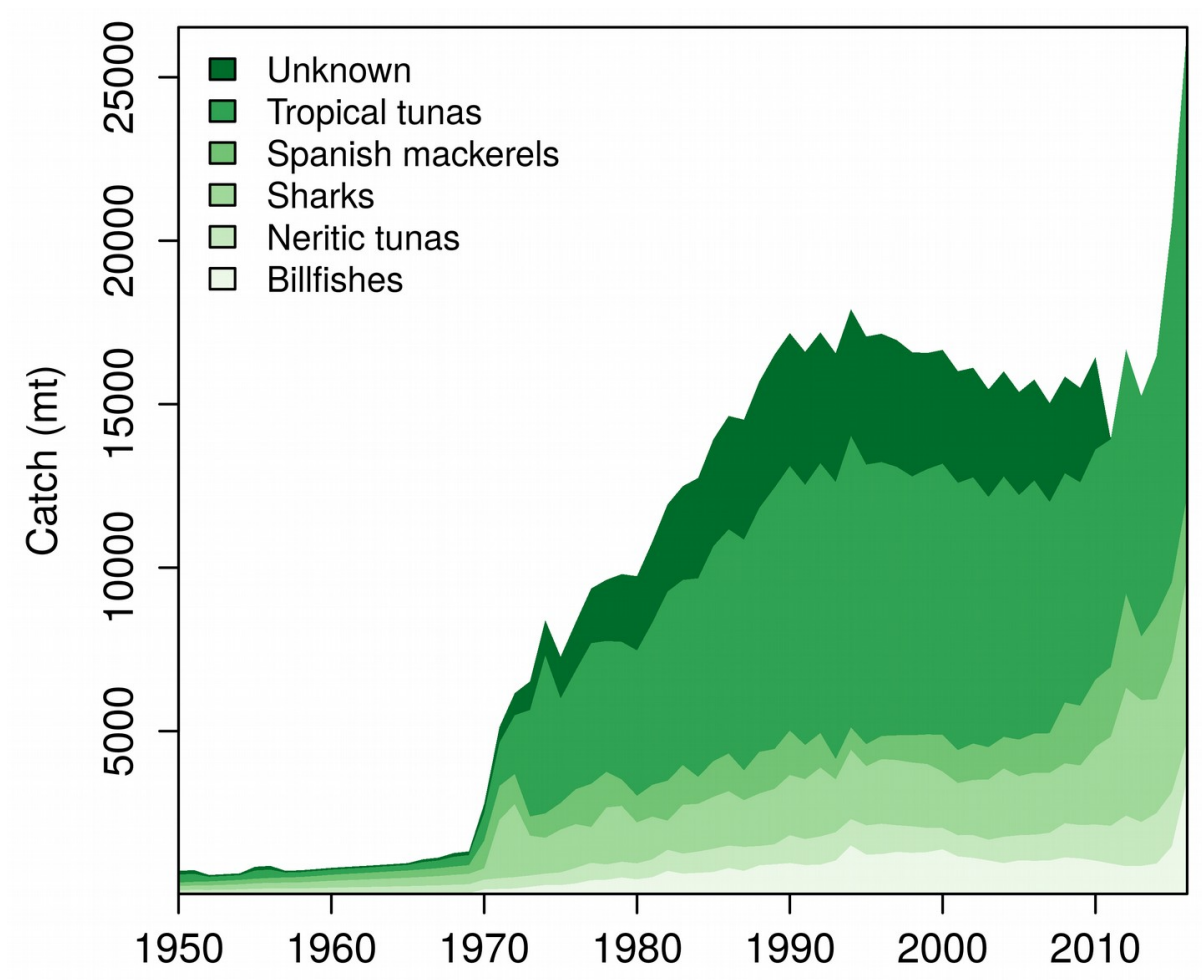

Fig. 3. Annual time series of catch (mt) by species group for the tuna and tuna-like species caught by the coastal fisheries of the countries bordering the Northern Mozambique Channel. 

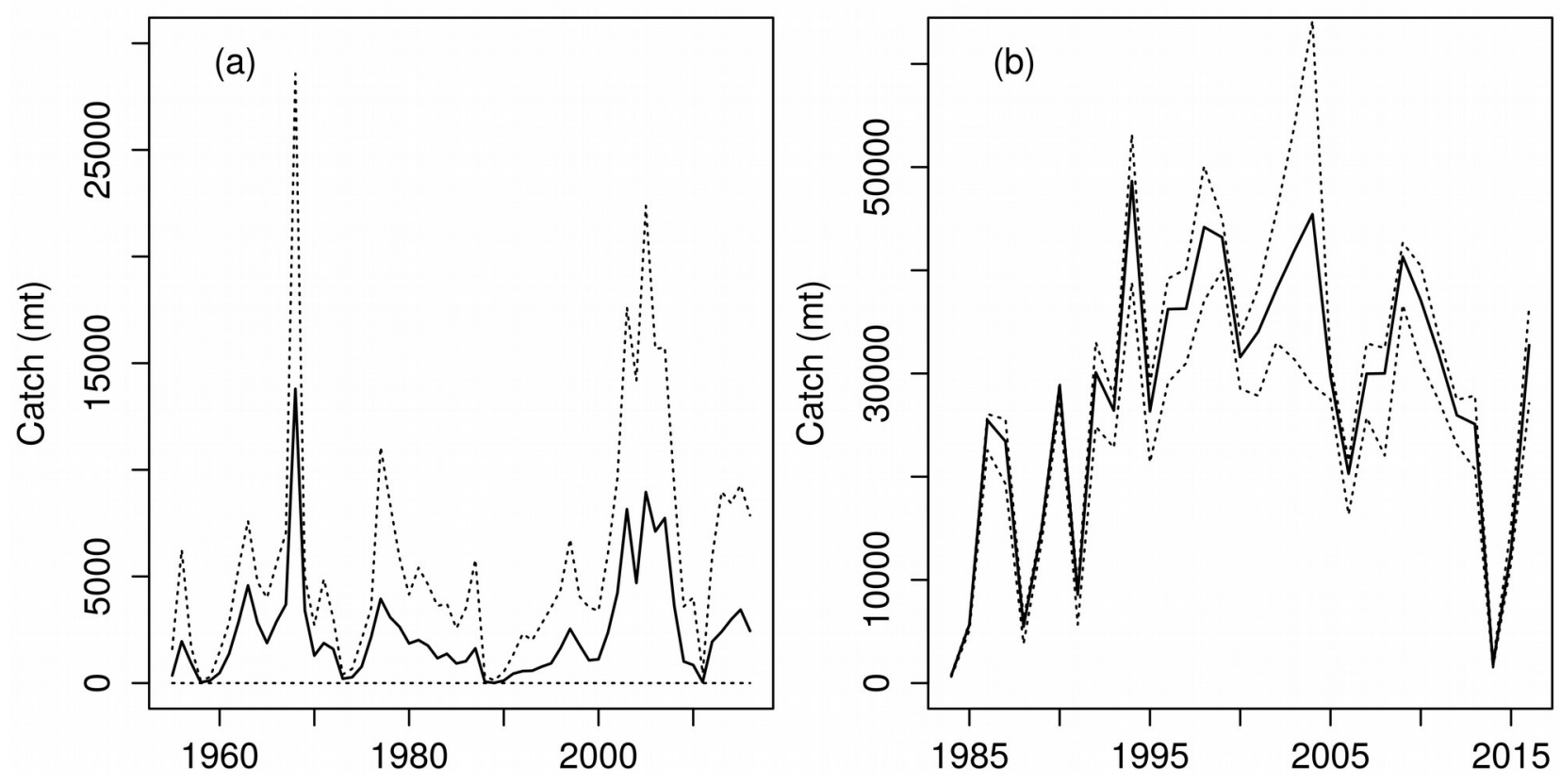

Fig. 4. Annual time series of tropical tuna catch of high seas (a) longliners and (b) purse seiners within the Northern Mozambique Channel (NMC). Solid line indicates estimates based on assumption of evenly distribution of the public-domain gridded catch intersected with NMC area. Dotted lines represents the uncertainty on catch estimated through lower and higher bounds based on assumptions of exclusion and inclusion of all catches intersected by NMC boundaries, respectively. 


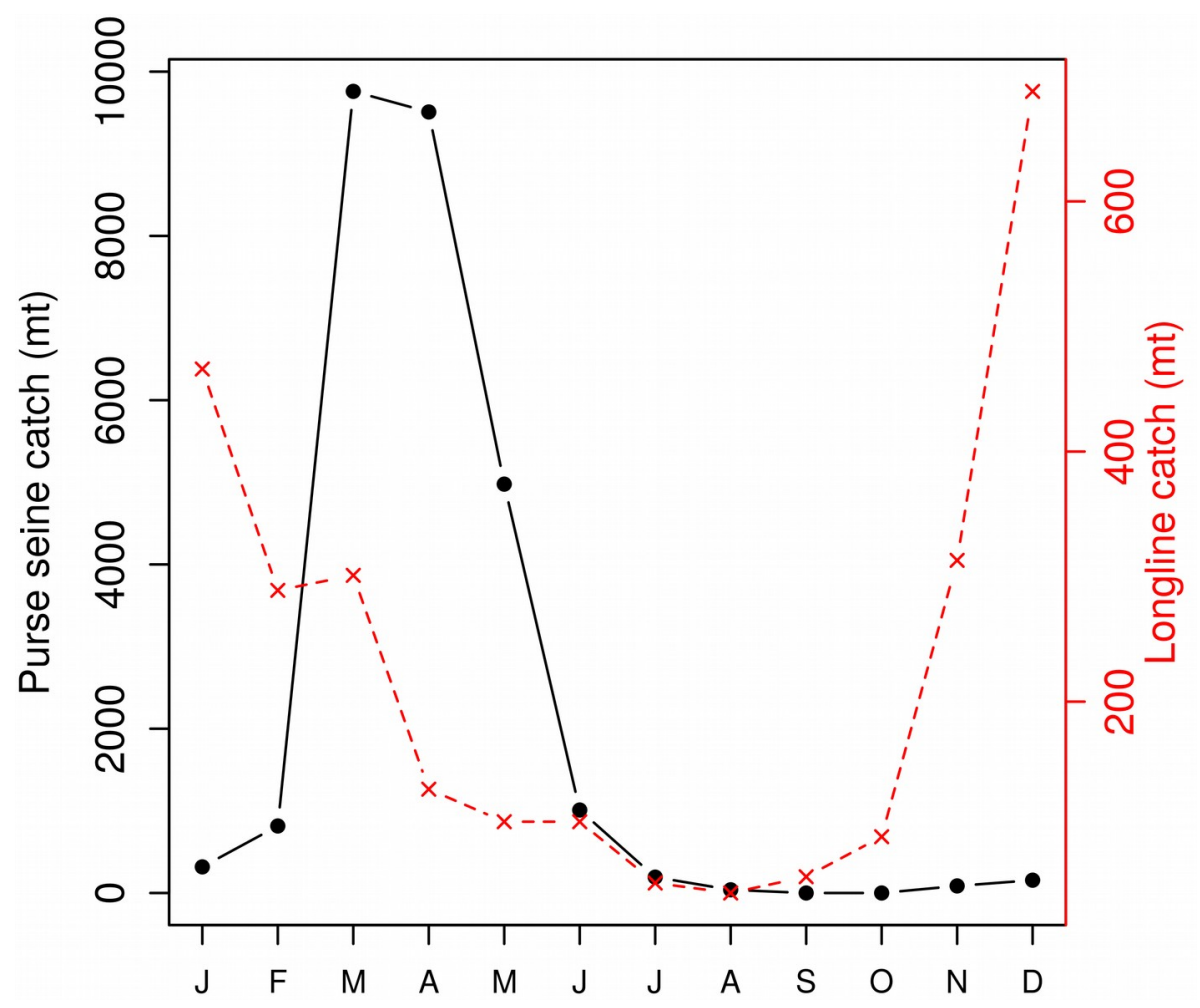

Fig. 5. Mean annual monthly catch (mt) of tropical tunas by high seas purse seiners (black solid line with dots) and longliners (red dashed line with crosses) during 2007-2016. 

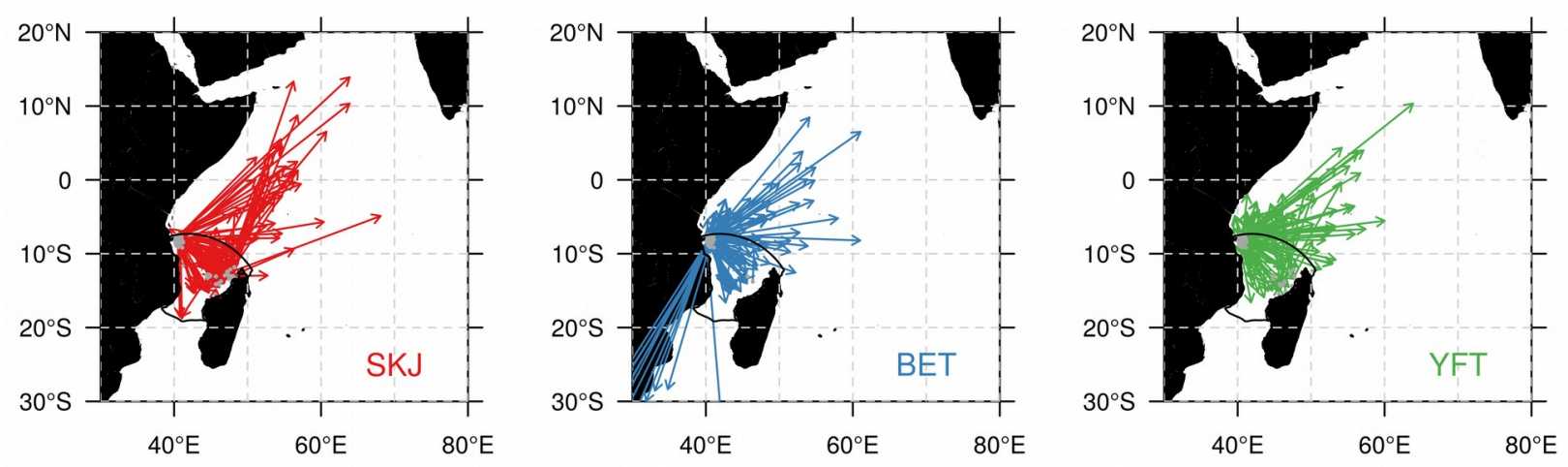

Fig. 6: Linear trajectories between tagging and recovery positions of skipjack (SKJ; $n=135$ ), bigeye (BET; $n=119)$, and yellowfin (YFT; $n=108)$ tagged with dart tags within the Northern Mozambique Channel (solid black line). Positions of tagging are indicated with grey open circles.

The number of mark-recaptures was sub-sampled for readability. 


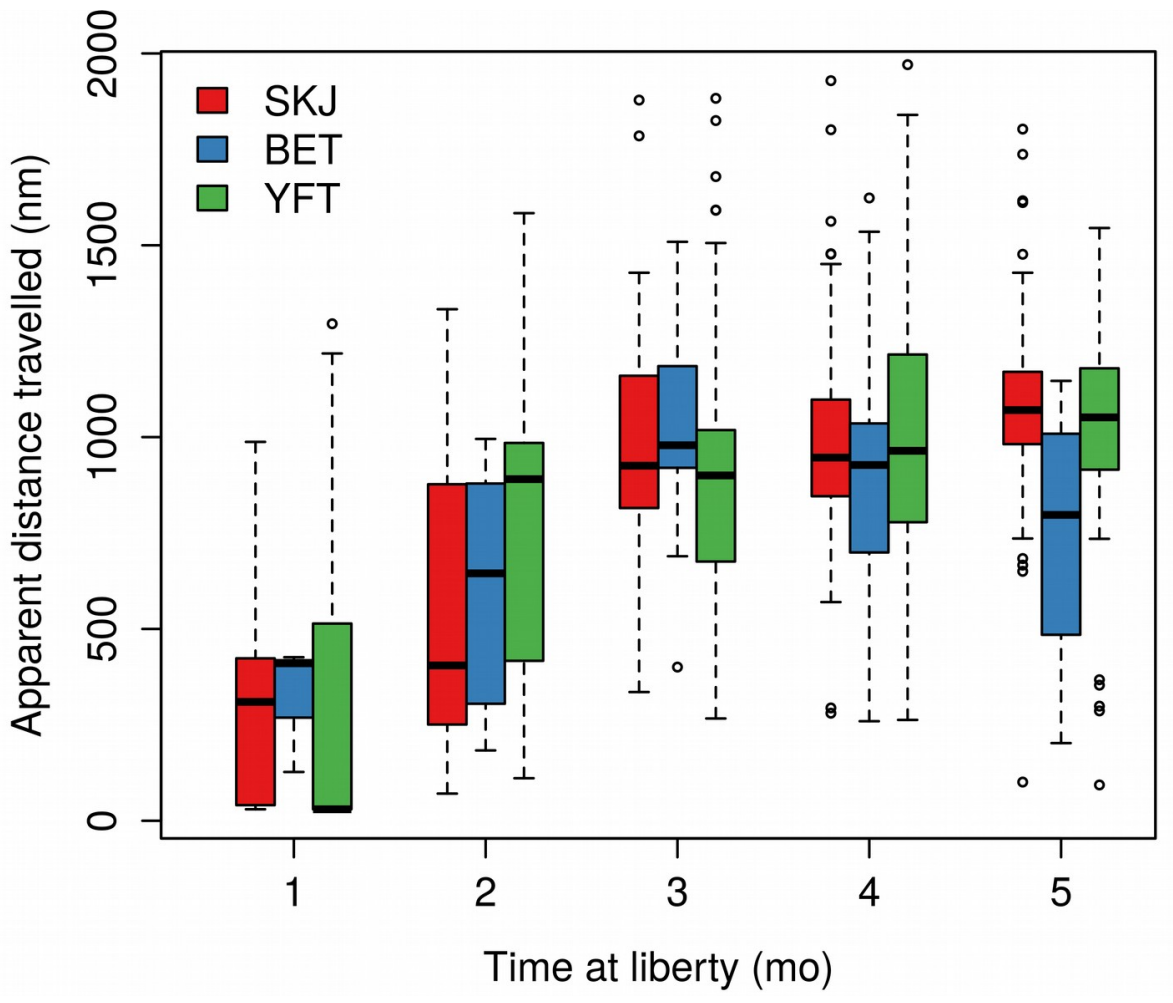

Fig. 7: Distribution of apparent distance travelled (nm) by month during the first 5 months at liberty of tropical tunas tagged with dart tags within the 


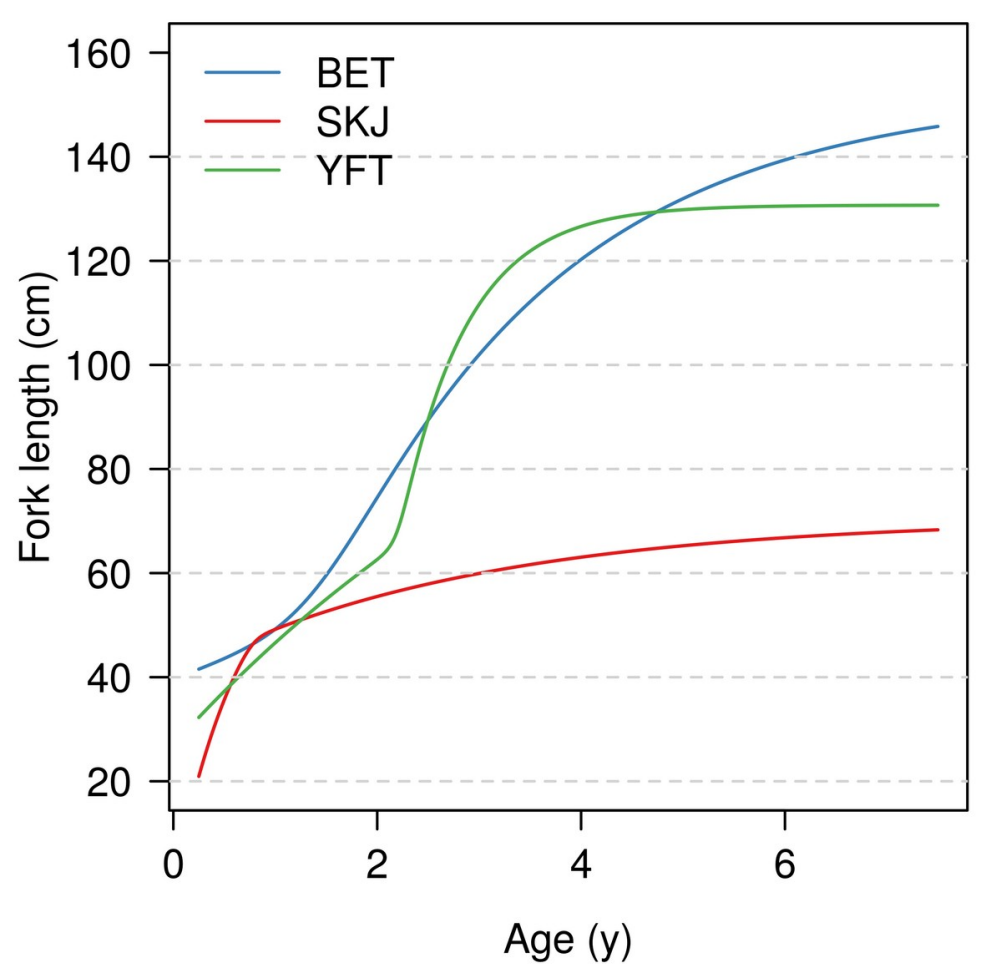

Fig. 8: Mean growth curves in fork length $(\mathrm{cm})$ for bigeye (BET), yellowfin (YFT), and skipjack (SKJ) tuna derived from integrated statistical models (Eveson et al. 2015). 


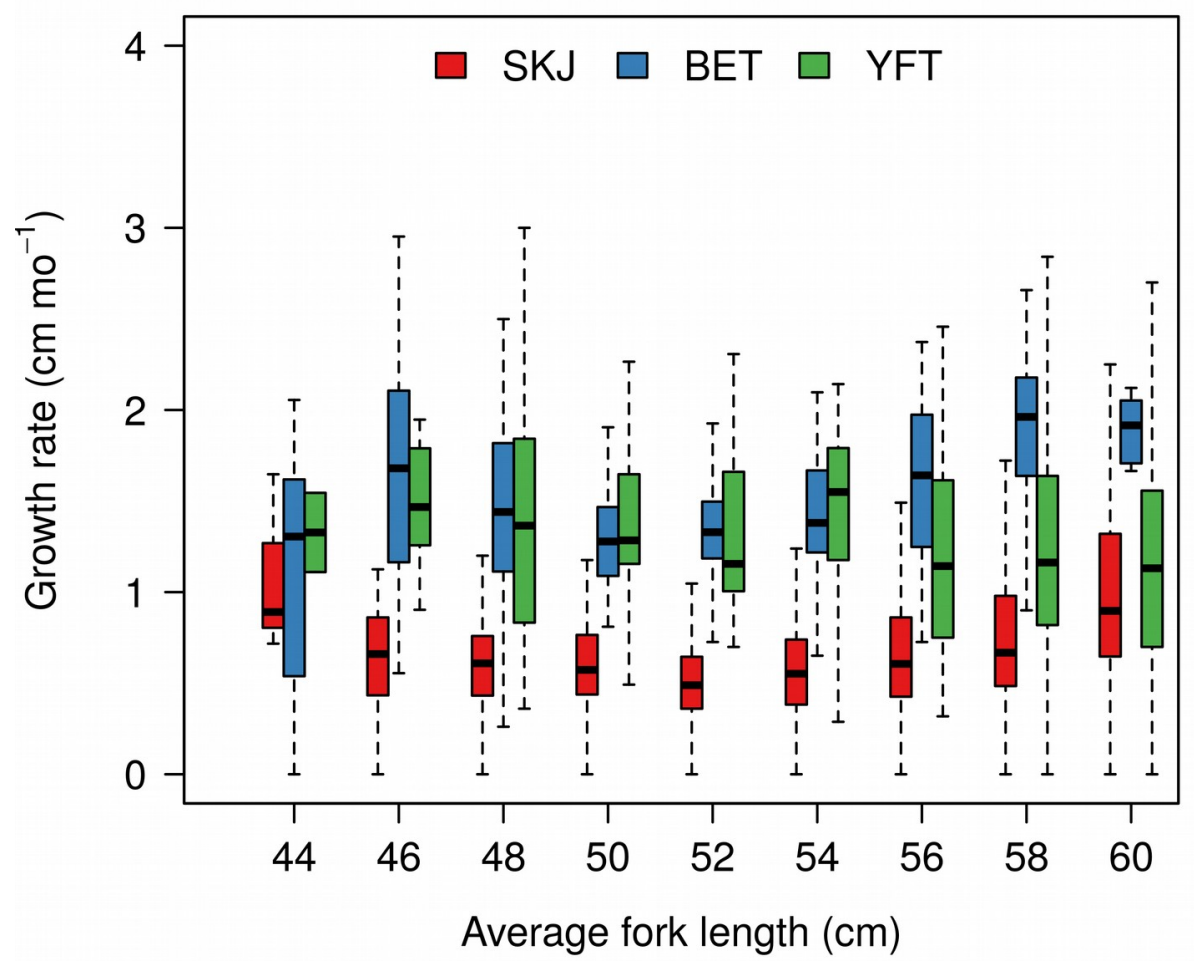

Fig. 9. Distribution of individual growth rates $\left(\mathrm{cm} \mathrm{mo}^{-1}\right)$ as a function of average length between tagging and recapture for skipjack (SKJ) and juveniles of bigeye (BET) and yellowfin (YFT) tagged with dart tags within the Northern Mozambique Channel. 


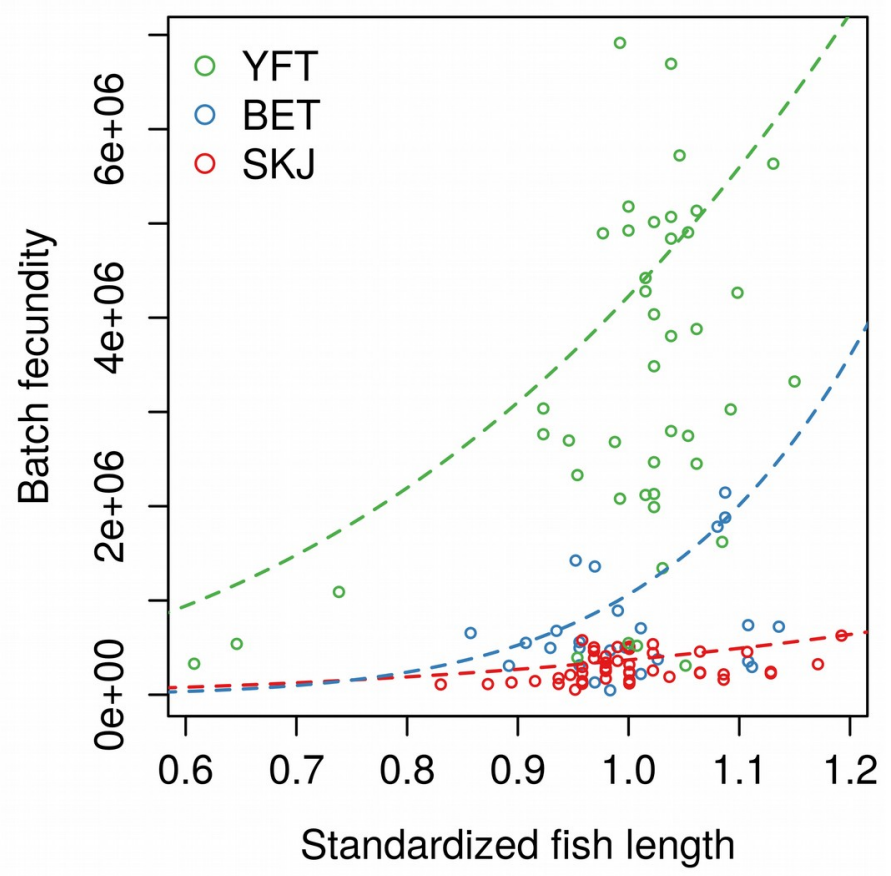

Fig. 10: Relationship between batch fecundity and 1005 indicate non-linear 75\% quantile regression models fitted to each data set. 

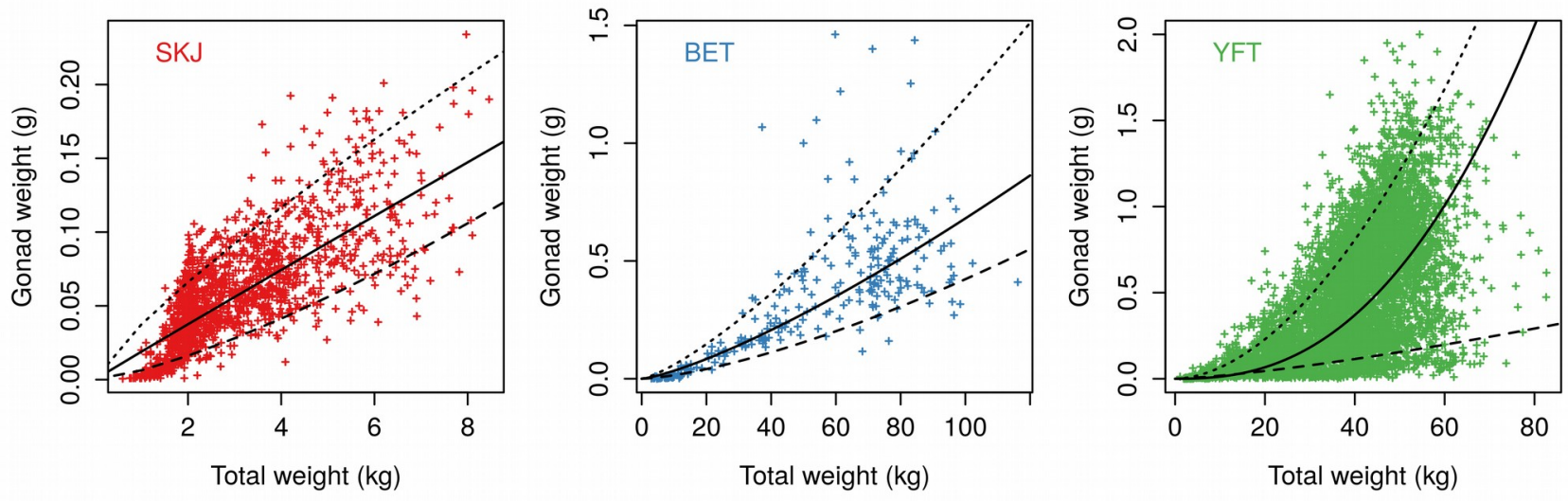

Fig. 11: Relationships between gonad weight $(\mathrm{g})$ and total weight $(\mathrm{kg})$ for Indian Ocean skipjack (SKJ), bigeye (BET), and yellowfin (YFT). Lines indicate 10\% (dashed), 50\% (solid) and 90\% (dotted) non-linear quantile regression models fitted to the data. 


\section{The key role of the Northern Mozambique Channel for Indian Ocean tropical tuna fisheries}

Emmanuel Chassot ${ }^{1,2, *}(0000-0002-6779-4955)$, Nathalie Bodin ${ }^{1,2}$ (0000-0001-8464-0213), Fany

Sardenne ${ }^{3}$, David Obura ${ }^{4}(0000-0003-2256-6649)$

${ }^{1}$ Seychelles Fishing Authority, PO BOX 449, Victoria, Mahé, Seychelles

${ }^{2}$ Institut de Recherche pour le Développement, UMR 248 MARBEC, Victoria, Seychelles

${ }^{3}$ MPO-DFO, Institut Maurice Lamontagne, 850 Route de la Mer, Mont-Joli, QC G5H 3Z4, Canada

${ }^{4}$ CORDIO East Africa, Mombasa, Kenya

\section{Materials \& Methods}

The IOTTP was conducted during 2002-2009 through several small-scale tagging projects and a larger regional component, the Regional Tuna Tagging Project (RTTP), to improve knowledge on the population dynamics of tropical tunas and strengthen the quality of management advices derived from stock assessments (Murua et al. 2015). More than 200000 tropical tunas were tagged with plastic dart tags and released in various areas of the western Indian Ocean, including the Mozambique Channel and along the coast of Tanzania where about 130000 tunas were tagged between July 2005 and August 2007 (Hallier and Fonteneau 2015). In addition, 6 pop-up tags were deployed on yellowfin tunas during the tagging operations off the coast of Tanzania in July-August 2007 but failed to transmit. Here, we used the mark-recapture data set of skipjack and juveniles of 
1042 yellowfin and bigeye tunas $(<80 \mathrm{~cm})$ tagged with dart tags within the NMC to (i) analyse their 1043 horizontal movements during the first 5 months at liberty inferred from tagging and recovery 1044 positions and (ii) estimate their growth rates. In both cases, we selected tunas tagged during the 1045 RTTP operations and characterized by reliable information on geographic position, species 1046 identification and length at both tagging and recapture events. A small number of growth rates 1047 values were found to be inconsistent with tuna growth. We therefore removed 188 mark-recapture 1048 data that had growth rates larger than the $97.5 \%$ quantile value of $4.28 \mathrm{~cm} \mathrm{mo}^{-1}$ and lower than the $10492.5 \%$ quantile of $0 \mathrm{~cm} \mathrm{mo}^{-1}$, i.e. excluding all fish showing apparent shrinkage between tagging and 1050 recapture (Table S1). For the analysis of growth rates, we finally selected the tunas of average fork 1051 length between tagging and recapture in the range 44-60 $\mathrm{cm}$ to balance the sampling design 1052 between the 3 species. First, we modelled the apparent distance travelled $(D$; nm) as a function of 1053 species $(S)$, average length between tagging and recapture $\left(L_{F} ; \mathrm{cm}\right)$, month of tagging $\left(M_{T}\right)$ and time 1054 at liberty $(T$; d) with generalized additive models (GAMs). GAMs make no a priori assumptions 1055 about the nature of the associations between predictors and response variables by using local 1056 smoothers (Hastie and Tibshirani 1990). Second, we modelled the growth rate ( $G$; $\mathrm{cm} \mathrm{mo} \mathrm{m}^{-1}$ ) between 1057 tagging and recapture as a function of $S, L_{F}, T$, and $M_{T}$ to describe and compare the growth of the 1058 three tropical tuna species when they mostly occur in association with floating objects. In both 1059 cases, spline function smoothers were used for modelling the effects of length $\left(L_{F}\right)$ and time at 1060 liberty $T$. Interaction between species $S$ and length $L_{F}$ was included in each model and tested for 1061 significance. Model fitting and automatic selection of the degrees of freedom for the regression 1062 splines were performed using the generalized cross-validation method (Wood and Augustin 2002) 1063 implemented in the mgcv package in $\mathrm{R}$ version 3.3.1 ( $\mathrm{R}$ Core Team 2016). The assumption of 1064 Gaussian error distributions was checked through the residuals. Each covariate was added to the 1065 model following a stepwise approach and selection of the best model was based upon the Akaike 1066 information criterion (AIC). Model predictions of daily distance travelled were made in the month 
1067 of May for (i) an average length of $56.9 \mathrm{~cm}$ corresponding to the average fork length between 1068 tagging and recapture observed in the data set to compare the horizontal movements between the 3 1069 tuna species and (ii) for values of fork length of 40, 50, and $60 \mathrm{~cm}$ for each species to illustrate the 1070 influence of size on the extent of the movements. Model predictions of growth rates were made 1071 using a time at liberty of 1 day to account for the smoothing effect of duration at liberty (Gaertner et 1072 al. 2010).

1074 References

Gaertner D, Chassot E, Fonteneau A, et al (2010) Estimate of the non-linear growth rate of yellowfin tuna (Thunnus albacares) in the Atlantic and Indian Ocean from tagging data. In: ICCAT Col. Vol. Sci. Pap. ICCAT, Madrid, Spain, pp 683-694

Hallier JP, Fonteneau A (2015) Tuna aggregation and movement from tagging data: A tuna "hub" in the Indian Ocean. Fisheries Research 163:34-43. doi: 10.1016/j.fishres.2014.06.003

Hastie T, Tibshirani R (1990) Generalized Additive Models. Chapman \& Hall, London, UK

Murua H, Eveson JP, Marsac F (2015) The Indian Ocean Tuna Tagging Programme: Building better science for more sustainability. Fisheries Research 163:1-6. doi: 10.1016/j.fishres.2014.07.001

R Core Team (2016) R: A Language and Environment for Statistical Computing. Vienna, Austria

Wood SN, Augustin NH (2002) GAMs with integrated model selection using penalized regression splines and applications to environmental modelling. Ecol Model 157:157-177. doi: 10.1016/S0304-3800(02)00193-X 
List of figures

1078 Fig. S1. Predictions of daily apparent distance travelled (nm) during the first 5 months of liberty for 1079 skipjack (SKJ), bigeye (BET) and yellowfin (YFT) tagged with dart tags within the Northern 1080 Mozambique Channel in the month of May and of average size between tagging and recovery of $108156.9 \mathrm{~cm}$ fork length. Dashed lines indicate mean \pm standard error.

1083 Fig. S2. Predictions of daily apparent distance travelled (nm) during the first 5 months of liberty for 1084 skipjack (SKJ), bigeye (BET) and yellowfin (YFT) tagged with dart tags within the Northern 1085 Mozambique Channel in the month of May and of average size between tagging and recovery of 40, 1086 50, and $60 \mathrm{~cm}$ fork length. Dashed lines indicate mean \pm standard error.

1088 Fig. S3. Predictions of growth rates $\left(\mathrm{cm} \mathrm{mo}^{-1}\right)$ for bigeye (BET), yellowfin (YFT), and skipjack 1089 (SKJ) tagged with dart tags within the Northern Mozambique Channel in the month of May. Dashed 1090 lines indicate mean \pm standard error.

Table S1. Description of the data sets used for modelling the apparent distance travelled between 1094 tagging and recovery locations in the first five months of liberty and average daily growth rates for 1095 skipjack, bigeye, and yellowfin tuna. $L_{T}=$ Fork length at tagging. $L_{R}=$ Fork length at recovery.

Table S2. Comparison of statistical models used for modelling (i) the horizontal movements during 1098 the first five months of liberty and (ii) the growth rates of skipjack and juveniles of yellowfin and 1099 bigeye tagged with dart tags within the North Mozambique Channel. Model formula, proportion of 1100 variance explained (adjusted r-squared), and difference in value of the Akaike information criterion 1101 ( $\triangle$ AIC) relative to a one parameter constant model. $D=$ apparent distance travelled (nm); $\mathrm{G}=$ 
1102 growth rate $\left(\mathrm{cm} \mathrm{mo}^{-1}\right) ; S=$ species (skipjack, bigeye or yellowfin); $T=$ time at liberty (d); $M_{T}=$ 1103 month of tagging; $L_{F}=$ average fork length between tagging and recapture $(\mathrm{cm}) ; \mathrm{s}=$ spline function 1104 smoother. 


\section{Figures}

1106

1107

1108

1109

1110

1111

1112

1113

1114

1115

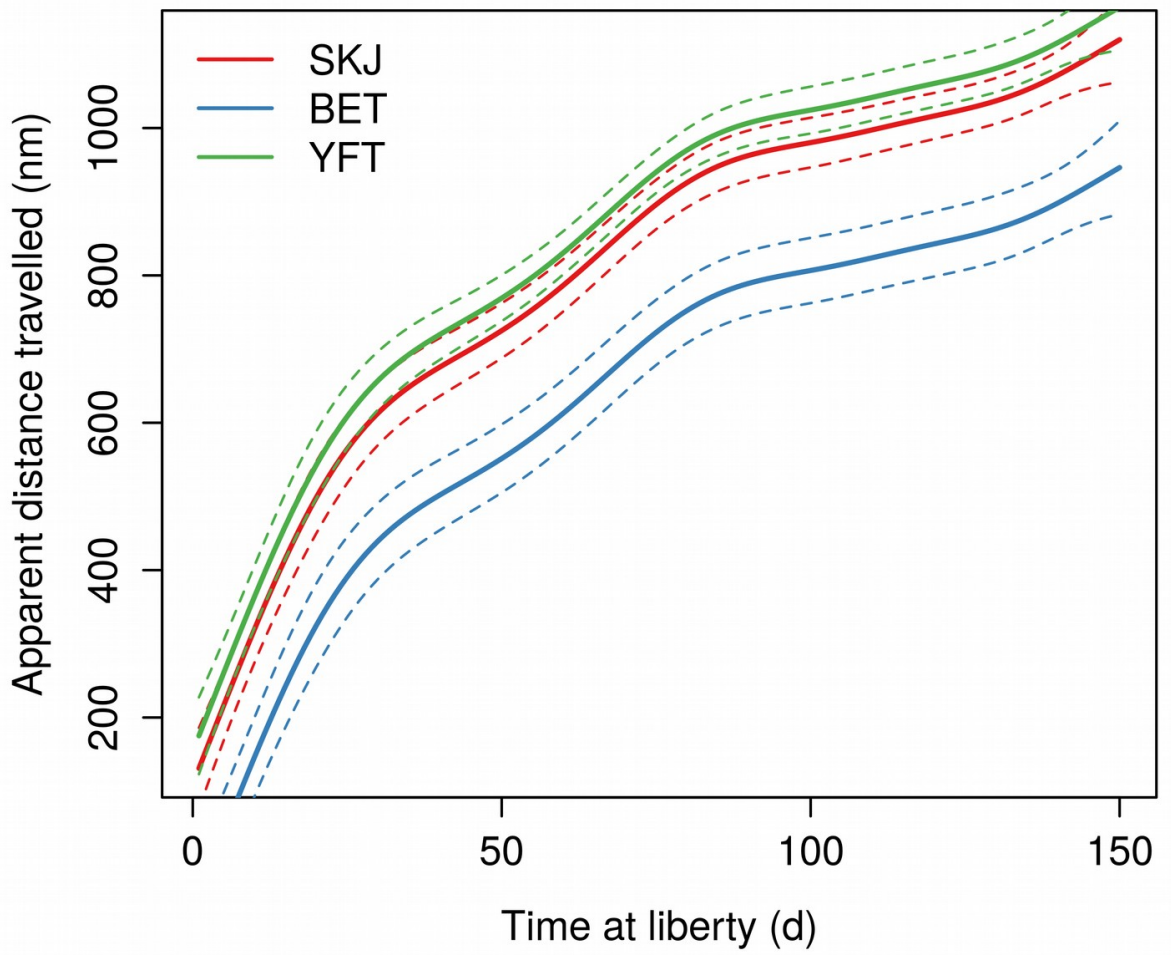

1116

Fig. S12: Predictions of daily apparent distance travelled (nm) during the first 5 months of liberty for skipjack (SKJ), bigeye (BET) and yellowfin (YFT) tagged with dart tags within the Northern Mozambique Channel in the month of May and of average size between tagging and recovery of $56.9 \mathrm{~cm}$ fork length. Dashed lines indicate mean \pm standard error.

1123 

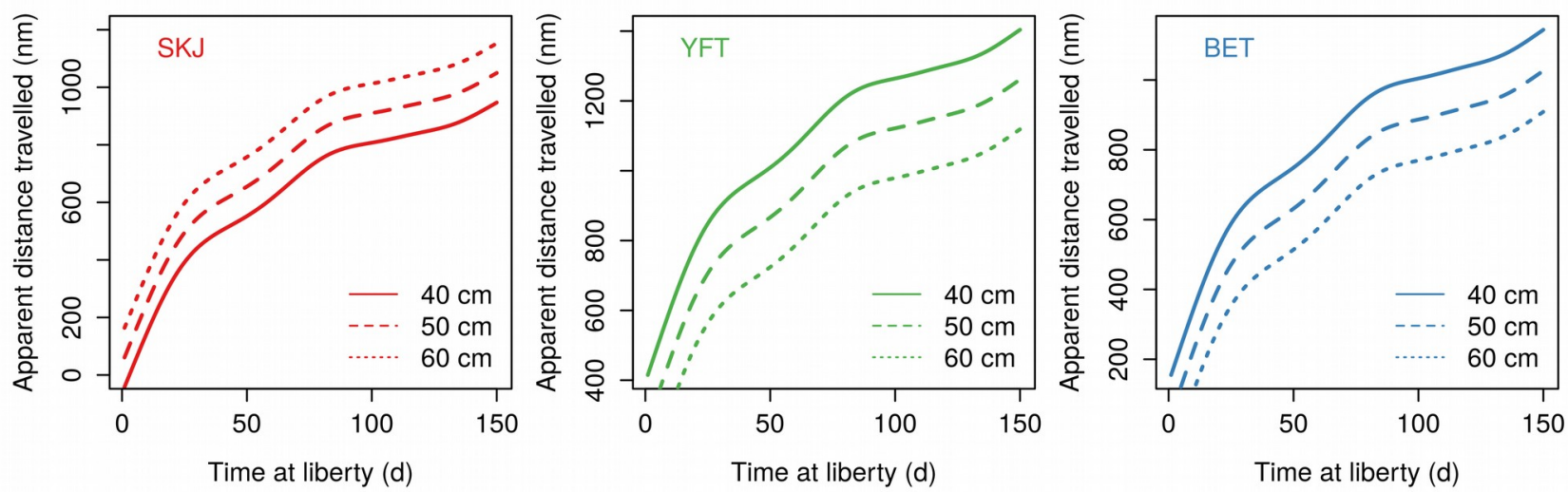

Fig. S13. Predictions of daily apparent distance travelled (nm) during the first 5 months of liberty for skipjack (SKJ), bigeye (BET) and yellowfin (YFT) tagged with dart tags within the Northern Mozambique Channel in the month of May and of average size between tagging and recovery of 40, 50, and $60 \mathrm{~cm}$ fork length. Dashed lines indicate mean \pm standard error. 


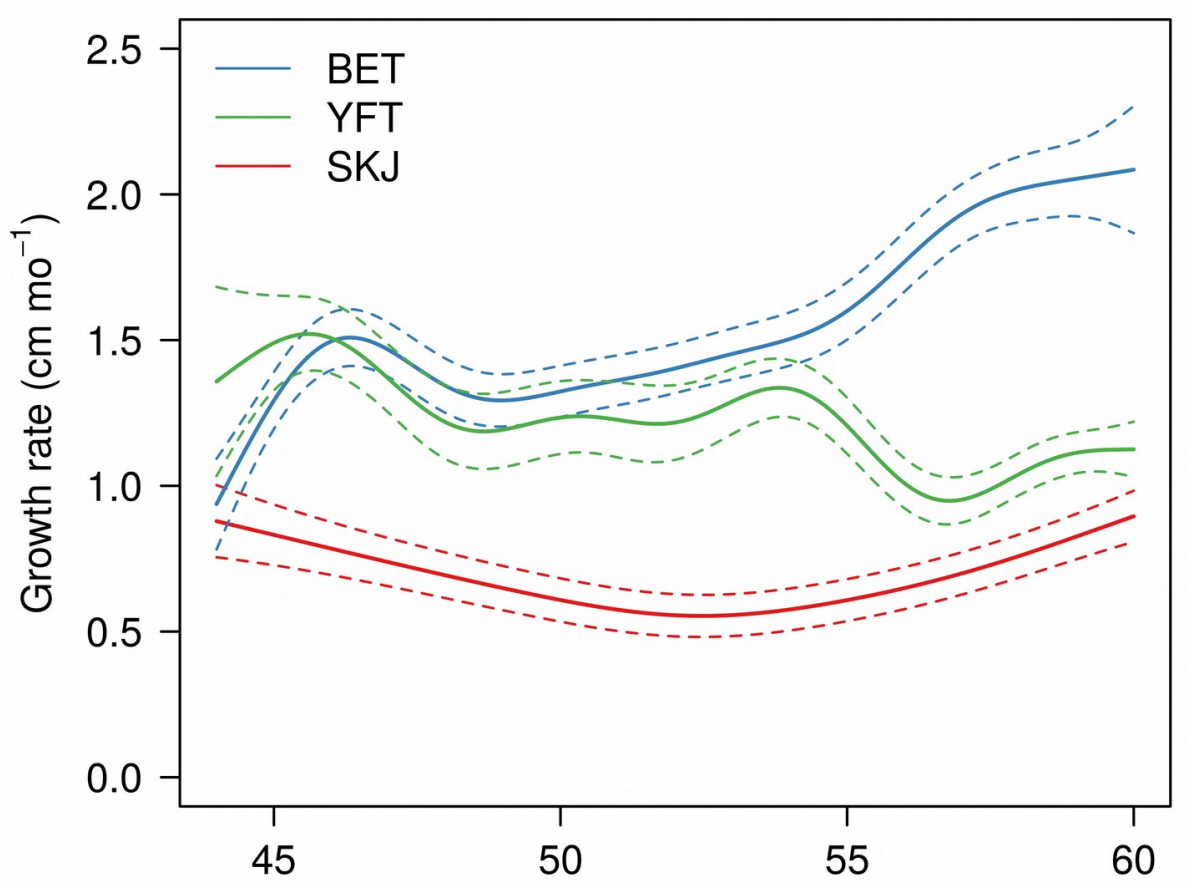

Fork length

Fig. S14. Predictions of growth rates $\left(\mathrm{cm} \mathrm{mo}^{-1}\right)$ for bigeye (BET), yellowfin (YFT), and skipjack (SKJ) tagged with dart tags within the 1145 Northern Mozambique Channel in the month of May. Dashed lines indicate mean \pm standard error.

1146 
1147 TABLES

1148 Table S1. Description of the data sets used for modelling the apparent distance travelled between 1149 tagging and recovery locations in the first five months of liberty and average daily growth rates for 1150 skipjack, bigeye, and yellowfin tuna. $L_{T}=$ Fork length at tagging. $L_{R}=$ Fork length at recovery.

\begin{tabular}{|l|r|r|r|r|r|}
\hline Species & \multicolumn{1}{|c|}{$\begin{array}{c}\text { Fish } \\
\text { number }\end{array}$} & \multicolumn{1}{c|}{$\begin{array}{c}\text { Range } L_{T} \\
(\mathrm{~cm})\end{array}$} & $\begin{array}{r}\text { Mean } \pm \text { SD } L_{T} \\
(\mathrm{~cm})\end{array}$ & $\begin{array}{c}\text { Range } L_{R} \\
(\mathrm{~cm})\end{array}$ & \multicolumn{1}{c|}{$\begin{array}{c}\text { Mean } \pm \text { SD } L_{R} \\
(\mathrm{~cm})\end{array}$} \\
\hline Distance travelled & & & & & \\
\hline BET & 270 & $43-68$ & $53.6( \pm 3.4)$ & $43-67$ & $56( \pm 3.9)$ \\
\hline SKJ & 424 & $33-71$ & $57.1( \pm 5.4)$ & $42.2-110$ & $60.8( \pm 6.3)$ \\
\hline YFT & & & & & \\
\hline Growth rates & 1236 & $37-58$ & $46.1( \pm 2.8)$ & $44-78.2$ & $57( \pm 5.7)$ \\
\hline BET & 348 & $38-59$ & $50.7( \pm 3.5)$ & $45-69$ & $56.5( \pm 3.7)$ \\
\hline SKJ & $39-60$ & $53.9( \pm 4.7)$ & $46-68.6$ & $58.3( \pm 3.8)$ \\
\hline YFT & & & &
\end{tabular}

1151 
1154 Table S2. Comparison of statistical models used for modelling (i) the horizontal movements during 1155 the first five months of liberty and (ii) the growth rates of skipjack and juveniles of yellowfin and 1156 bigeye tagged with dart tags within the North Mozambique Channel. Model formula, proportion of 1157 variance explained (adjusted r-squared), and difference in value of the Akaike information criterion 1158 ( $\triangle$ AIC) relative to a one parameter constant model. $D=$ apparent distance travelled $(\mathrm{nm}) ; \mathrm{G}=$ 1159 growth rate $\left(\mathrm{cm} \mathrm{mo}^{-1}\right) ; S=$ species (skipjack, bigeye or yellowfin); $T=$ time at liberty (d); $M_{T}=$ 1160 month of tagging; $L_{F}=$ average fork length between tagging and recapture $(\mathrm{cm}) ; \mathrm{s}=$ spline function 1161 smoother.

\begin{tabular}{|c|c|c|}
\hline Model & Adjusted $r^{2}$ & $\Delta \mathrm{AIC}$ \\
\hline \multicolumn{3}{|l|}{ Model 1: Distance travelled } \\
\hline$D \sim S+T+M_{T}$ & 0.317 & -289.7 \\
\hline$D \sim S+s(T)+M_{T}$ & 0.387 & -369.8 \\
\hline$D \sim S+s(T)+L_{F}+M_{T}$ & 0.403 & -389.2 \\
\hline$D \sim S+s(T)+s\left(L_{F}\right)+M_{T}$ & 0.418 & -404.5 \\
\hline$D \sim S+s(T)+L_{F}+M_{T}+L_{F}: M_{T}$ & 0.429 & -402.7 \\
\hline \multicolumn{3}{|l|}{ Model 2: Growth rate } \\
\hline$G \sim S+L_{F}+M_{T}+T$ & 0.407 & -1005.6 \\
\hline$G \sim S+L_{F}+M_{T}+s(T)$ & 0.411 & -1013.3 \\
\hline$G \sim S+s\left(L_{F}\right)+M_{T}+s(T)$ & 0.426 & -1054 \\
\hline$G \sim S+s\left(L_{F}\right): T+M_{T}+s(T)$ & 0.456 & -1149.6 \\
\hline
\end{tabular}

